REVISTA DE DERECHO UNED, núm. 6, 2010

\title{
LA DISCRIMINACIÓN POR MOTIVOS ÉTNICOS O DE RAZA: ALTERNATIVAS PARA GESTIONAR LA DIVERSIDAD EN LAS EMPRESAS
}

\author{
SONIA PRIETO GONZÁLEZ \\ Ana M. ${ }^{a}$ Marcos DEL CANO
}

La sociedad, es de por sí, diversa...la empresa es solo un reflejo de esa diversidad

(Agrupación de Desarrollo NEXOS)

Resumen: Bajo el título «la discriminación por motivos étnicos o de raza: alternativas para gestionar la diversidad cultural en las empresas», se propone un ejercicio de reflexión y análisis sobre las soluciones y alternativas para gestionar la diversidad que el fenómeno migratorio ha traído a nuestra sociedad y que ya forma parte de nuestra vida cotidiana: empleo, vivienda, ocio, etc.

Se centra en cómo abordar este reto en el ámbito de la empresa, desterrando las prácticas discriminatorias que existen actualmente en los procesos de contratación, desarrollo de la actividad laboral y finalización de la relación de trabajo. Ya que se entiende que la presencia de nuevas culturas y formas de entender la vida y por tanto la actividad laboral, puede resultar muy enriquecedor para la gestión de las empresas, desde el punto de vista humano y económico.

Para ello, después de dibujar el escenario de nuestra sociedad desde el punto de vista de la inmigración y su situación en el mundo laboral y empresarial, y observar cuáles son las líneas estratégicas e iniciativas ya abordadas en este ámbito por Administraciones y organizaciones sociales, se presenta un modelo de gestión de la diversidad basado en los modelos actuales de Responsabilidad Social Corporativa. 


\begin{abstract}
Under the title «ethnic or race discrimination: alternatives for managing cultural diversity in business», it is proposed an exercise of reflection and analysis around alternative solutions for managing diversity that inmigration has meant to our society and which now is part of our daily lives: employment, housing, leisure, etc.

It focuses on how to address this challenge in the field of business, banishing the discriminatory practices that exist currently in the recruitment process, development of work activity and completion of the employment relationship. It is clear that the presence of new cultures and ways of understanding life and therefore work activity can be very enriching for the company management from a human and economic point of view.

To do this, after drawing the scenario of our society from the point of view of immigration and its status in work and business, observing what are the strategies and initiatives in this area already addressed by government and social organizations, a model of diversity management based on current models of Corporate Social Responsibility is presented.
\end{abstract}

Sumario: 1. Introducción.-1.1. España, entorno multicultural.-2. Discriminación en el escenario económico.-2.1. ¿Qué es discriminación?.-2.2. ¿Se discrimina en el mercado laboral español?-3. Instrumentos de lucha frente a la discriminación.-3.1. Instrumentos jurídicos.-3.2. Iniciativas puestas en marcha por organizaciones sociales.-4. Otras alternativas: combatir la discriminación «acercando los dos polos».-4.1. Un punto de partida: Responsabilidad Social Corporativa e Innovación Social; La gestión de la diversidad cultural; La responsabilidad social corporativa como modelo de incorporación de la gestión de la diversidad cultural.-4.2. Otras propuestas; Metodología de trabajo.-5. Conclusiones.-6. Bibliografía de referencia.

\title{
1. INTRODUCCIÓN
}

\subsection{España, entorno multicultural}

Es innegable que la sociedad española está inmersa en un proceso de cambio, referido en innumerables ocasiones en monografías, artículos de prensa, medios de comunicación. España es un país receptor de inmigración ${ }^{1}$. Pero no es un mero contenedor. Es, como cualquier

${ }^{1}$ En la última década, el crecimiento de la población española se ha visto influenciado por el acusado incremento que ha experimentado la población extranjera 
otro contexto de convivencia de personas, un laboratorio permeable de encuentros y desencuentros de muy diversas culturas, razas, religiones, costumbres, que llegan de aquí y de allí, tal vez incluso de más allá. Es una realidad a la que no podemos dar la espalda, por mucho que nos empeñemos, por mucho que nuestras tradiciones sigan rebosando nuestros calendarios y jornadas festivas en verano. España es, hoy más que nunca, un país multicultural. Un crisol donde culturas diferentes, de dentro y de fuera, convergen sin posibilidad de retorno a un camino distinto. Pues ello sin duda sería una huida hacia adelante, un perder el tren sin expectativas de nueva estación.

Admitir este cambio implica igualmente admitir que ni la sociedad, ni las Administraciones Públicas españolas estaban preparadas para asumir e integrar este fenómeno con la rapidez con que se ha producido. Y la realidad es que la presencia de un número importante de personas inmigrantes ha hecho surgir situaciones no deseables de discriminación por el origen racial o étnico en diferentes ámbitos de nuestra vida social, como pueden ser el empleo, la educación o la vivienda. Combatirla e idear escenarios de integración e intercambio debe ser por tanto uno de los objetivos de los agentes sociales y económicos a todos los niveles.

\section{Las cifras}

Como ya se ha apuntado, en la última década España se ha convertido en uno de los principales destinos de la migración internacional, con un saldo anual medio de 575.000 personas entre 2001 y 2008.

residente en España. En el periodo que va desde el 1 de enero de 1999 a la misma fecha de 2009, la población española ha crecido en seis millones de personas (exactamente 6.025.345 personas), mientras que la población extranjera con autorización de residencia (con datos a 31 de diciembre del año anterior) lo ha hecho en cerca de cuatro millones (3.753.852 residentes más). Ello supone que el 62,30\% del crecimiento de la población de España se debe a los extranjeros con autorización de residencia o certificado de registro en vigor. Existen muchos documentos al respecto que hacen mención de las grandes cifras. Véase por ejemplo: Ministerio de Trabajo y Asuntos Sociales. Plan Estratégico de Ciudadanía e Integración 2007-2010. Madrid, 2006 (http://www.mtas.es/es/migraciones/Integracion/PlanEstrategico/indice.htm); Ministerio de Trabajo e Inmigración. Boletín estadístico de extranjería e inmigración, n. ${ }^{\circ} 19$, febrero 2009. Madrid 2009 (extranjeros.mtin.es); COLECTIVO IOÉ. ¡No quieren ser menos! Exploración sobre la discriminación laboral de los inmigrantes en España. Comisión Ejecutiva Confederal UGT. Madrid, octubre 2001. Véase A. M. MARCOS DEL CANO, «Inmigración y Minoría», en O. PÉREZ DE LA FUENTE (ed.): Una discusión sobre la gestión de la diversidad cultural, 2008, Madrid, Instituto de Derechos Humanos «Bartolomé de las Casas», Universidad Carlos III de Madrid, pp. 55-82. 
Ello explica el importante crecimiento que ha experimentado la población total del país en los últimos años, que ha pasado de 41 a 46 millones de habitantes (unido a la baja tasa de natalidad de la población «autóctona» y la mayor juventud de estos nuevos ciudadanos):

Población total, inmigrada y extranjera en España (19712008)

\begin{tabular}{|c|c|c|c|c|c|c|c|c|}
\hline & Año & $\begin{array}{c}\text { A } \\
\text { Pobl. Total }\end{array}$ & $\begin{array}{c}\text { B } \\
\text { Inmigrantes }\end{array}$ & $\begin{array}{c}\% \\
\mathbf{B} / \mathbf{A}\end{array}$ & $\begin{array}{c}\mathrm{C} \\
\text { Extranjeros }\end{array}$ & $\begin{array}{c}\% \\
\text { C/A }\end{array}$ & $\begin{array}{c}\text { D } \\
\text { Residentes }\end{array}$ & $\begin{array}{c}\%(\mathbf{C}-\mathbf{D}) / \mathbf{C} \\
\text { «Irregulares» }\end{array}$ \\
\hline \multirow{3}{*}{$\overline{0}$} & 1971 & 34.117 .623 & 365.376 & 1,1 & 183,195 & 0,5 & 148.400 & 19,00 \\
\hline & 1981 & 37.723 .299 & 625.907 & 1,7 & 233.082 & 0,6 & 183.422 & 21,3 \\
\hline & 1991 & 38.846 .823 & 840.504 & 2.2 & 350.062 & 0,9 & 278.696 & 20,4 \\
\hline \multirow{8}{*}{ 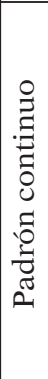 } & 2001 & 41.116 .842 & 1.969 .270 & 4,8 & 1.370 .667 & 3,3 & 895.720 & 34,7 \\
\hline & 2002 & 41.837 .894 & 2.594 .052 & 6,2 & 1.977 .944 & 4,7 & 1.109 .060 & 43,9 \\
\hline & 2003 & 42.717 .064 & 3.302 .440 & 7,7 & 2.664 .168 & 6,2 & 1.324 .001 & 50,3 \\
\hline & 2004 & 43.197 .684 & 3.693 .806 & 8,6 & 3.034 .326 & 7,0 & 1.647 .011 & 45,7 \\
\hline & 2005 & 43.975 .375 & 4.355 .300 & 9,9 & 3.691 .547 & 8,4 & 1.977 .291 & 46,4 \\
\hline & 2006 & 44.708 .964 & 4.837 .622 & 10,8 & 4.144 .166 & 9,3 & 2.738 .932 & 33,9 \\
\hline & 2007 & 45.200 .737 & 5.249 .993 & 11,6 & 4.519 .554 & 10,0 & 3.021 .808 & 33,1 \\
\hline & $2008 *$ & 46.063 .511 & 5.995 .962 & 13,0 & 5.220 .577 & 11,3 & 3.979 .014 & $23,8^{*}$ \\
\hline
\end{tabular}

Todo ello convierte a España en el décimo país del mundo por número total de inmigrados, pasando página de esta forma a su «tradicional» condición de "país de emigración»:

\section{Principales colectivos de extranjeros e inmigrantes en España (2008)}

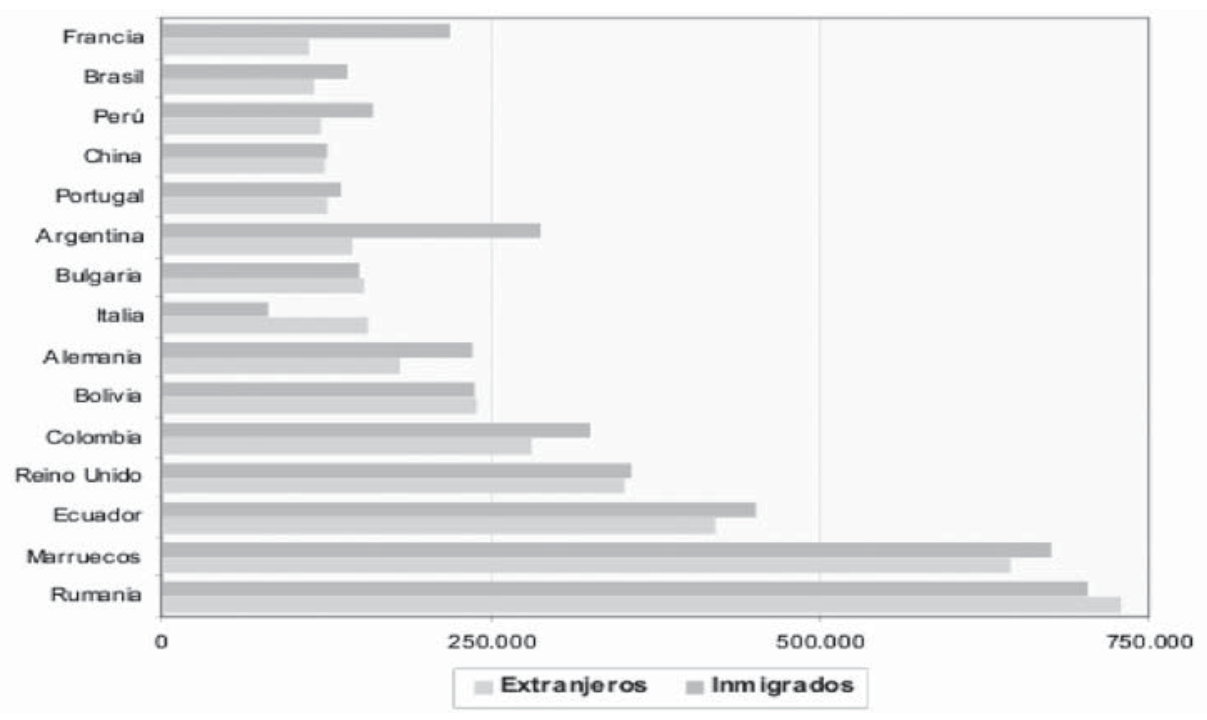


Como decimos, esta importante presencia de personas inmigrantes en nuestra sociedad tiene indudables efectos en ella. Sin embargo, y contra lo que en muchas ocasiones se viene a pensar, estas consecuencias no son negativas, sino que por el contrario en la práctica totalidad de las casuísticas analizadas desde diferentes ámbitos es posible argumentar los beneficios y ventajas que aporta la presencia de este colectivo $^{2}$. Así, por ejemplo, desde el punto de vista de la economía del país, existen informes técnicos elaborados desde la administración y el sector privado que avalan junto con la OCDE la extraordinaria aportación de la inmigración como una de las claves del buen comportamiento de la economía española entre 1995 y 2005 en términos de crecimiento, empleo y finanzas públicas. Las personas inmigrantes, incluyendo a quienes no están documentados («sin papeles»), explicaría el 30\% del crecimiento del PIB entre esos años, y casi el 50\% del empleo creado entre los años 2000 y 2005. En 2005 los residentes extranjeros aportaron el 6,6\% del presupuesto público, generando un gasto un $20 \%$ inferior, dando lugar a un saldo positivo que representó en su momento el $50 \%$ del superávit registrado por todas las administraciones públicas. Así, cuando desde ciertos ámbitos se atribuye a la inmigración la degradación de servicios como la sanidad o la educación, no se tiene en cuenta que tales servicios deberían aumentar conforme crece el número de beneficiarios (más cotizantes), que además están aportando a las arcas públicas más de lo que perciben.

Por otro lado, las personas inmigrantes han impulsado la demanda de bienes y servicios en diversos ámbitos como pueden ser la vivienda o la alimentación, generando nuevas líneas de negocio y favoreciendo de esta forma el crecimiento de nuevos sectores económicos. Han sido decisivos en la expansión del transporte público de las ciudades y de larga distancia, del mercado logístico (i.e., mensajería), de la venta de móviles, de coches de segunda mano, etc. Han recuperado el concepto de vivienda en alquiler y son nuevo perfil de cliente para entidades financieras y los nuevos productos que están surgiendo, pensados sobre todo para estas personas.

Si seguimos aportando datos, vemos que en lo laboral han proporcionado una oferta de mano de obra en sectores hasta entonces deficitarios, como la agricultura o el servicio doméstico. Y en cuanto

2 COLECTIVO IOÉ. ¡No quieren ser menos! Exploración sobre la discriminación laboral de los inmigrantes en España. Comisión Ejecutiva Confederal UGT. Madrid, octubre 2001. También, MINISTERIO DE ASUNTOS SOCIALES. Plan Estratégico de Ciudadanía e Integración 2007-2010. Madrid 2006 (http://www.mtas.es/es/migraciones/ Integracion/PlanEstrategico/indice.htm) 
a educación se refiere, ha suplido en parte el importante descenso de alumnado de los últimos quince años, lastrado por la caída de la natalidad.

Estos datos, sin embargo, son los que dan estudios no siempre difundidos con la suficiente intensidad, que conocen quienes ya trabajan en este ámbito y por tanto, ya están «concienciados», por decirlo de alguna manera. Los prejuicios hacia los inmigrantes siguen alimentando la idea de que constituyen uno de los principales problemas de la España actual (el cuarto, según el CIS ${ }^{3}$, después del paro, el terrorismo y la vivienda). Son supuestamente los responsables de que aumente la inseguridad ciudadana, el paro, y todos los demás caballeros apocalípticos que cabalgan en nuestra sociedad, especialmente en este momento de crisis. Ello se favorece además por una información en muchos casos alarmista y sesgada, no sólo desde algunos medios de comunicación sino también lamentablemente por parte de ciertos políticos ${ }^{4}$. Sin embargo, según el Ministerio del Interior, el número de delitos por habitante en España descendió un $22.7 \%$ entre 2002 y 2006, período en el que la inmigración creció un $86,5 \%$.

La realidad por tanto, se presenta compleja, puesto que no se trata tanto de una integración entendida como asimilación, cuanto de una incorporación a la sociedad desde la diversidad en igualdad de oportunidades, y la lealtad al marco legal de convivencia y tolerancia en libertad. Supone la construcción de un espacio social y político nuevo, con herramientas para gestionar la diversidad cultural en sus múltiples dimensiones y desde los diferentes ámbitos en los que actúa.

\subsection{Objeto del estudio}

El presente trabajo lleva por título «la discriminación por motivos étnicos o de raza: alternativas para gestionar la diversidad cultural en las empresas». Se trata de un título genérico, que en suma quiere lle-

\footnotetext{
3 Véase último Barómetro del CIS en http://www.cis.es/cis/opencm/ES/1_ encuestas/estudios/ver.jsp? estudio $=9660$

4 En el año 2002, el entonces Ministro de Interior, Mariano Rajoy, declaró en una comparecencia en el Senado que «nueve de cada diez reclusos preventivos en las cárceles españolas son extranjeros». Con esta declaración, parecía querer explicarse que el incremento de la delincuencia en 2001 y primeros meses de 2002 se debía al aumento de la inmigración. Puede verse en COLECTIVO IOÉ. Ciudadanos o Intrusos: la opinión pública española ante los inmigrantes (http://www.bantaba.ehu.es/obs/ ocont/obsinter/doc/ciudintrus/)
} 
var a abordar la cuestión del trato discriminatorio que en muchos casos sigue padeciendo el colectivo inmigrante en el mercado laboral, desde el momento de acceder, o intentar acceder a un puesto de trabajo, pasando por las diferentes situaciones que pueden darse en el desarrollo de su actividad laboral hasta llegar finalmente al término de la relación contractual.

No queremos presentar sin embargo este estudio como un análisis culpabilizador de los agentes sociales y económicos, de las empresas, de los sindicatos, etc.; el objetivo es plantear soluciones y alternativas, desde el convencimiento de que la presencia de nuevas culturas y formas de entender la vida y por tanto la actividad laboral, puede resultar muy enriquecedor para la gestión económica de las empresas, tanto desde el punto de vista humano (entendida la empresa como organización social, como entidad viva que crece y se nutre de los recursos que en ella y con ella interaccionan) como desde el punto de vista económico (crecimiento, competitividad, calidad de servicio, ...). Se trata por tanto de plantear dónde estamos en este momento, cuáles son las incertidumbres, las dudas, los miedos que en muchos casos llevan a situaciones discriminatorias; para finalmente presentar las propuestas que ya existen como alternativas.

A la hora de hablar de alternativas, nos ha parecido interesante desechar el término «combatir la discriminación» y sustituirlo por el de «gestionar la diversidad». Creemos que es un enfoque positivo y necesario para comenzar desde el principio acercando posturas y destruyendo roles o posiciones enfrentadas. Desde esta perspectiva, hemos detectado líneas estratégicas de actividad a nivel de la Unión Europea y del Estado, que deberán traducirse en medidas concretas, más allá de planes estratégicos y normativas que queden tan sólo en el papel. A ello hay que añadir las iniciativas que ya se han puesto en marcha por diversas organizaciones sociales, con mayor o menor éxito, pero que suponen sin duda un punto de partida en este intento de gestionar adecuadamente la diversidad cultural de nuestra economía.

Por último, el estudio que presentamos no quiere limitarse a una simple exposición de la situación y lo que puede llegar a hacerse, sino que pretende ser «atrevido» $\mathrm{y}$, en este sentido, plantear un modelo concreto de gestión de la diversidad que tome como referencia los modelos actuales de Responsabilidad Social Corporativa, entendiendo que las herramientas de gestión de calidad que incluyen pueden servir de referente para el desarrollo de sellos de calidad o iniciativas similares que motiven a las empresas a incorporar tales medidas en sus centros de trabajo. 


\section{DISCRIMINACIÓN EN EL ESCENARIO ECONÓMICO}

\section{1. ¿Qué es discriminación?}

Discriminar significa diferenciar, distinguir, separar una cosa de otra. Es una situación en la que una persona o grupo es tratada de forma desfavorable a causa de prejuicios, derivados generalmente de su pertenencia a una categoría social distinta, como pueden ser la raza, la orientación sexual, la religión, el rango socioeconómico, la edad, o la discapacidad.

Es interesante en este sentido el planteamiento que sobre la discriminación realiza el Colectivo IOÉ ${ }^{5}$, entendiendo el concepto como «cualquier postergación, segregación o minusvaloración que un grupo ejerce sobre otro cuando tal proceso excluyente viene asociado a una diferencia entre ambos colectivos. Las personas particulares son discriminadas, al margen de sus valores y comportamientos individuales, por su adscripción a tales grupos marcados por esa diferencia. La discriminación tiene lugar entre dos polos: el grupo discriminante o activo, y el grupo discriminado o pasivo. Implica por tanto una práctica de poder que produce un estatus de inferioridad en las víctimas de la discriminación ${ }^{6} »$.

Este concepto lo desarrollan en el siguiente gráfico:

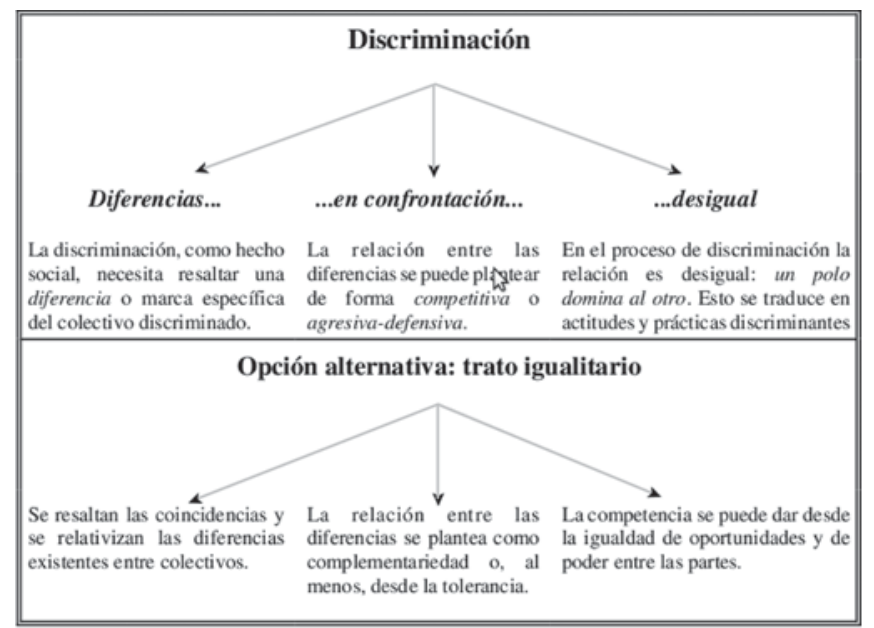

Fuente: PEREDA Carlos, DE PRADA Miguel Ángel, ACTIS Walter (Colectivo IOÉ) Discriminación de los inmigrantes en el trabajo. En «Sociedad y Utopía», n. ${ }^{\circ} 16,2000$, pp. 91-102. También en http://www.nodo50.org/ioe/investigaciones_articulos.php?op=articulo\&id=48.

5 www.nodo50.org/ioe

6 PEREDA C., DE PRADA M.A., ACTIS W. (Colectivo IOÉ) Discriminación de los inmigrantes en el trabajo. "Sociedad y Utopía», n. ${ }^{\circ} 16,2000$, pp, 91-102. (http://www.nodo50.org/ioe/investigaciones_articulos.php?op=articulo\&id=48) 
La discriminación puede darse por tanto en diferentes ámbitos y afectar a muy diversos colectivos, y lamentablemente es una realidad que ha existido y sigue existiendo en todos los países del mundo, bajo formas diversas, pese a la amplia legislación nacional e internacional y el reconocimiento de la igualdad y la no discriminación como derecho humano fundamental. Revela ante todo una discapacidad social a la hora de gestionar la diferencia, traduciéndose en actitudes y situaciones de preeminencia de un grupo sobre otro, que terminan por minar la convivencia social en una escalada que no tiene fin.

En el caso de la discriminación que sufre o puede sufrir el colectivo inmigrante, concurren principalemente cinco diferencias ${ }^{7}$ que «favorecen» esta situación:

1. La nacionalidad. La mayor discriminación se produce con respecto a los inmigrantes indocumentados.

2. La cultura. La discriminación tiene lugar con respecto a las culturas minoritarias cuando la mayoritaria se siente superior o cuando esta considera que aquella puede contaminar o perjudicar la cohesión social que proporciona la cultura dominante.

3. El fenotipo. Es la discriminación que se produce por diferencias en la imagen corporal, como puede ser el color de la piel u otros rasgos físicos.

4. La posición económica. Las diferencias de acceso, condiciones de trabajo y participación en la renta originan diversas formas de discriminación, que también afectan al colectivo inmigrante cuando intentan sobrevivir alternando empleos precarios y temporadas en paro. No entrarían aquí los inmigrantes "cualificados», es decir, los que tienen un trabajo reconocido en empresas solventes.

5. El género. Como el caso anterior, esta diferencia afecta a todos los colectivos, siendo aquí la mujer la que sufre este tipo de discriminación.

Estas diferencias, ya sea individualmente o en su conjunto pueden llegar a ser fuente de intercambio enriquecedor, y tal es el objetivo del presente estudio, demostrar que lo que en origen mueve a discriminar

7 GLICK, N., BASCH, L. y BLANC-SZANTON, C. (de) Towards a transnational perspective on migration. Race, class, ethnicity and nationalism reconsidered. The New York Academy of Sciences, New York, 1992. 
puede enriquecer y mejorar la sociedad de origen. Sin embargo, la realidad es que todavía en la mayoría de los casos la diferencia se sigue viviendo desde la confrontación y las relaciones de poder entre las partes.

La población inmigrante puede percibir la discriminación de diferentes maneras. En el ámbito laboral puede significar para algunos la imposibilidad de acceder a un determinado puesto para el que están cualificados, para otros puede implicar el no poder acceder a ningún puesto de trabajo en absoluto. La intensidad o la gravedad de las desventajas que afrontan depende del número de características personales que llegan a suscitar esa discriminación, y la manera en que estas actúan entre sí. Por ejemplo, una persona puede ser diferente por su raza o por el color de su piel. Además puede ser mujer. Además puede estar discapacitada, y tener cierta edad. Todo ello puede generar situaciones de gran complejidad, y sean diferencias consideradas de forma individual, o como hemos indicado en este ejemplo, todas juntas, acarrean desventajas sociales y económicas que a la larga provoca inestabilidad política y agitación social, perturbando la inversión y el crecimiento económico ${ }^{8}$.

Antes de pasar a analizar la situación concreta del inmigrante en el mercado laboral español, y valorar las posibles alternativas para afrontar la discriminación y sustituirlo por fórmulas de gestión de la diversidad, interesa matizar el concepto de discriminación por motivos étnicos o de raza.

Se suele hablar de discriminación racial en el ámbito laboral para referirse a los obstáculos que de forma arbitraria impiden o dificultan el ingreso y desarrollo en dicho mercado de las personas que forman parte de otras comunidades o minorías, cuya identidad se funda en características religiosas o culturales, o incluso en la ascendencia nacional, diferentes a las de la sociedad receptora. En los últimos años, el modelo de los flujos migratorios ha modificado los modelos de discriminación racial contra los trabajadores migrantes, segundas y terceras generaciones de migrantes y ciudadanos extranjeros, de manera que ya no es sólo la nacionalidad la que suscita discriminación, sino otros factores como por ejemplo la religión o la cultura.

8 ORGANIZACIÓN INTERNACIONAL DEL TRABAJO. Informe Mundial de la OIT: Insidia e inseguridad - la nueva cara de la discriminación y la desigualdad en el ámbito del trabajo. Revista de la OIT, n. ${ }^{\circ}$ 59, Abril 2007. (http://www.ilo.org/wow/ PrintEditions/lang_es/docName-WCMS_091707/index.htm) El Informe afirma que «estas barreras a la igualdad pueden impedir que las sociedades aprovechen plenamente las posibilidades que brinda la economía globalizada en la actualidad». 
A ello se suma la situación actual de crisis, que agudiza las tensiones discriminatorias ya que en algunos casos se produce una competencia entre nacionales (sobre todo en los sectores marginales de la fuerza de trabajo) y los trabajadores migrantes, que si hasta ese momento habían cubierto el déficit de mano de obra en sectores como la agricultura o el servicio doméstico, ahora son cuestionados precisamente por la situación de crisis económica y la falta de empleo generalizado. A la desconfianza por la diferencia cultural y de identidad se suma ahora la competencia por un puesto de trabajo.

Como podemos observar, hablar de discriminación racial para referirnos a la discriminación que sufre el colectivo inmigrante es insuficiente porque no cubre todas las situaciones que pueden llegar a darse. Son varios los autores que hablan de un nuevo concepto de racismo ${ }^{9}$, que no se refiere tanto a razas cuando a culturas y que bajo el pretexto de defender la diversidad cultural, lo que realmente está promoviendo en la separación entre ellas o la segregación en "guetos» diferenciados. Las nuevas formas de racismo por tanto van más allá del «racismo biológico» aunque se sigan cargando las tintas en las diferencias que presentan los extranjeros, como si ya de por sí implicara una naturaleza diferente a la española y por ello potencialmente arriesgada para una convivencia pacífica y para la pervivencia de la cohesión social de la cultura autóctona. De esta forma, los inmigrantes son calificados como intrusos si pretenden competir con los españoles en pie de igualdad, en derechos laborales, sociales o políticos.

\section{2. ¿Se discrimina en el mercado laboral español?}

Según los resultados de la encuesta Eurobarómetro ${ }^{10}$ sobre las actitudes frente a la discriminación, la mayoría de los ciudadanos europeos piensan que el origen étnico o la religión, entre otros factores, pueden constituir un obstáculo a la hora de encontrar un empleo, incluso en igualdad de cualificaciones. La mayoría de los encuestados se declara opuesto a toda forma de discriminación, y considera que las minorías étnicas son más propensas a sufrir conductas discrimi-

9 Ver BAKER, M. The New Racism, Junction Books, London, 1981; GALLISSOT, R., Misère de l'antirazisme, Éditions de l'Arcantère, Paris, 1985; y TAGUIEFF, R., La force du préjugué, Paris, 1987.

${ }_{10}$ COMISIÓN EUROPEA. Special Eurobarometer 296. July 2008 (http://ec.europa. eu/public_opinion/archives/ebs/ebs_296_en.pdf) 
natorias. La encuesta revela igualmente que una quinta parte de las personas encuestadas declara haber sido testigo directo de una discriminación por motivos étnicos (oscilando desde el 15\% en Irlanda hasta el 35\% en los Países Bajos).

En España, el sentimiento expresado por la ciudadanía encuestada, ya sea a través del Eurobarómetro, ya sea con otro tipo de encuestas, es similar, en el sentido de un rechazo a la discriminación en cualquier de sus formas. Sin embargo, es una realidad el hecho que las actitudes discriminatorias siguen presentes e incluso creciendo, aumentando el número de «no tolerantes» frente al de «tolerantes», así como la percepción de la inmigración como problema, aun sin llegar a escalar posiciones relevantes ${ }^{11}$.

Esta esquizofrenia de sentimientos en el imaginario colectivo no es algo novedoso, que haya surgido de repente con el fenómeno migratorio, aunque sea cierto que ello haya contribuido a que "reverdezca». En efecto, como crisol de culturas que ha sido España desde la antigüedad, desde siempre se ha producido esa ambivalencia de sentimientos encontrados como lugar de cruce, confrontación y convivencia: musulmanes, judíos, gitanos, han convivido y padecido diferentes formas de discriminación y actitudes racistas.

Cuatro siglos después, España se encuentra de nuevo con el fenómeno de la inmigración y la pluralidad cultural. Por otra parte, el contexto económico de las nuevas migraciones se caracteriza por una creciente globalización del sistema mundial y la intensificación de estrategias neoliberales para gestionar la fuerza de trabajo. La nueva fase de crecimiento capitalista se basa de forma cada vez más intensa en la producción de bienes inmateriales (nuevas tecnologías, etc.) aplicada a una economía de servicios y polarizada en torno a ciertos sectores. Ello afecta a grupos importantes de población a nivel mundial, que dejan de ser necesarios para el sistema, ni como productores ni como consumidores. Hay por tanto un excedente de población, por decirlo de alguna manera, concentrada sobre todo en

11 Si repasamos los Barómetros del CIS desde el año 2000, podemos observar que a juicio de los entrevistados y de forma mayoritaria, los principales problemas en España son el paro y los problemas económicos, el terrorismo y la inmigración. Desde el año 2000 hasta el Barómetro de julio de 2009, la posición de los problemas económicos y del terrorismo ha variado en función de la coyuntura política y económica del momento, por lo que se explica que actualmente sea la cuestión económica precedida del paro la que más preocupación provoca a los españoles. La inmigración es un asunto que permanece en los primeros puestos del Barómetro, que tiene una importancia secundaria para los encuestados pero que va en progresivo crecimiento. Ver http://www.cis.es/cis/opencms/ES/2_barometros/\# 
economías del Sur con poca participación en los flujos económicos transnacionales, así como a ciertas franjas de población de países centrales.

La tendencia a la segmentación de la fuerza de trabajo se impone en todo el mundo, asistiendo a una creciente desregulación del mercado de trabajo que ahonda en esa segmentación, polarización y precarización de los trabajadores asalariados, con importantes bolsas de desempleo e inmigración laboral ocupada en empleos tradicionales pero vinculados al crecimiento económico (i.e., construcción de viviendas, agricultura de exportación, etc.). Además, los niveles de protección social, las redes de cobertura sociales y familiares, las expectativas y los estilos de vida y trabajo llevan a hacer «inadecuados» ciertos empleos para muchos parados autóctonos. Y así pasan a ser ocupados por los extranjeros ${ }^{12}$.

En España, las condiciones de trabajo en el mercado laboral presentan un cuadro diverso y polarizado, desde el punto de vista del acceso e implicación en la actividad económica así como desde la perspectiva del grado de participación en la renta producida. En este contexto se sitúa el trabajador inmigrante, que acusa una diversificación de situaciones aún más acusada que la media española; además, una buena parte de este colectivo queda "encerrado» en ciertos nichos laborales con peores condiciones de trabajo y escasas posibilidades de promoción. A ello hay que añadir la circunstancia de que no existe un perfil homogéneo de trabajador inmigrante, sino una polarización interna de peso basada en diferentes factores: procedencia nacional y cultural, cualificaciones, tiempo de llegada, género, etc.

Para poder atisbar una comprensión de los motivos por los que se discrimina en el trabajo a las personas inmigrantes, hay que partir de la discriminación que en general puede sufrir este colectivo en su vida diaria, y no sólo a la hora de conseguir o realizar un trabajo. En este sentido, diferentes investigaciones empíricas han permitido distinguir tres grandes lógicas en los discursos de los españoles sobre los ex-

12 Esta situación se mantiene relativamente hasta fechas actuales, cuando la crisis económica mundial ha puesto contra las cuerdas al colectivo de parados autóctonos y ha llevado a «reivindicar» puestos de trabajo en sectores que se habían convertido de ocupación «habitual» por personas inmigrantes. A ello han contribuido sin duda las desafortunadas declaraciones y/o iniciativas de ciertos grupos políticos, que lejos de aportar soluciones, no hacen sino favorecer sentimientos discriminatorios que ahondan en esa brecha esquizofrénica de sentimientos encontrados en el imaginario español («yo no soy racista, pero...»). 
tranjeros. Por ejemplo, siguiendo al Colectivo IOÉ se pueden distinguir ${ }^{13}$ :

a) Lógica nacionalista: la pertenencia a un estado es una realidad incuestionable que adscribe a las poblaciones a un estatus de ciudadanía. Lo normal es que cada población resida en su espacio estatal, por lo que las migraciones internacionales son una anomalía a este orden de cosas y, en caso de que se produzcan, la prioridad en el acceso a los recursos ha de corresponder a los nacionales del Estado receptor.

b) Lógica culturalista: el discurso gira en este caso en torno a la diferencia cultural. Al margen de las circunstancias económicas, la coexistencia de colectivos con culturas «incompatibles» sólo puede saldarse con la asimilación o con la segregación absoluta (los de fuera sólo pueden ser aceptados si se asimilan, en tanto no lo hagan hay que sospechar de ellos y no otorgarles derechos excesivos). La identidad se construye en torno a la idea de "normalidad», a un molde prefijado culturalmente fuera del cual todo lo demás es paradigma de anormalidad y desviación, contrario a las costumbres vigentes en España. Desde estos presupuestos la diferencia cultural no tiene legitimidad y la convivencia entre culturas es imposible, por lo de que se defiende la asimilación de los diferentes o su aislamiento. En otros casos, y desde esta misma lógica, la diversidad de culturas no representa una pluralidad de opciones con igual entidad sino una estructura jerárquica en la que la cultura superior, a sazón la española, ha de imponerse a la inferior, la de los otros. El caso más extremo en esta lógica identificada sería el denominado «nacionalismo fascista», que aúna el rechazo nacional y el cultural, bien para justificar una más intensa explotación laboral de ciertos inmigrantes, ya para justificar otras formas de agresión.

c) Lógica igualitaria. En este caso se parte de la igualdad básica de los seres humanos para generar diferentes tipos de discursos, que van desde la igualdad de oportunidades en un mundo económicamente abierto hasta la crítica al ordenamiento social vigente. En esta lógica encontramos desde las posturas que afirman que el éxito o el fracaso depende de las propias capacidades, y por tanto postula a favor de la oportunidad para los

13 COLECTIVO IOÉ. ;No quieren ser menos! Exploración sobre la discriminación laboral de los inmigrantes en España. Comisión Ejecutiva Confederal UGT. Madrid, octubre 2001. 
inmigrantes como para cualquier otra persona, con independencia de la tasa de paro en el país de destino, pasando por la idea de unión entre todos los trabajadores como víctimas de la explotación derivada del capitalismo, hasta llegar a quienes entienden que la convivencia entre culturas diversas es un valor positivo y factor de enriquecimiento mutuo.

En general, los discursos sobre los extranjeros están muy condicionados por la posición social del que habla. No hay un referente unívoco de los discursos que hablan de ello, porque rápidamente se filtran contenidos que refieren criterios muy típicos del imaginario español, a la sazón los criterios de clase por ejemplo, que como ya hemos indicado es un factor de discriminación reconocido en el mercado nacional, con independencia de la idea de raza o cultural. Lo más habitual es expresar un sentimiento de "arriba hacia abajo», es decir, las referencias discriminatorias confunden en casi todos los casos aspectos culturales con ideas de clase y de inferioridad con respecto a las personas discriminadas. De esta forma, los inmigrantes con quienes tenemos más identidad, ya sea de clase, étnica o cultural, pierden a nuestros ojos los rasgos de extranjeridad que potencialmente podrían discriminarles (se acepta a estudiantes norteamericanos, a inversores japoneses, ...). Por lo que los argumentos étnicos y nacionales se combinan con los de clase para articular un campo de rechazo atravesado por ese doble eje (y a veces triple, si tenemos en cuenta el aspecto de género). La articulación de «lo extranjero» se construye de esta forma en un proceso que vincula la posición de clase y sus opciones ideológicas.

La discriminación en el trabajo se produce, en primer lugar, en el acceso al empleo, ya sea por factores institucionales (leyes discriminatorias ${ }^{14}$ ) o por la mentalidad de los empresarios y compañeros de trabajo. A nivel de los empresarios, a la lógica que se aplica en muchos sectores económicos para la maximización del beneficio, se suman ciertas conductas discriminatorias basadas en motivos étnicos, prejuicios asociados a la raza o cultural del solicitante de empleo que condicionan la concesión o no del puesto de trabajo.

Además, la política gubernamental de inmigración ha hecho depender la estabilidad jurídica de los trabajadores extranjeros de su si-

14 En principio no es el caso en el Estado Español. Veremos en un apartado posterior de este documento cómo tanto en el texto constitucional como en leyes posteriores se han incorporado disposiciones que reconocen el principio de igualdad y contemplan medidas específicas de lucha contra la discriminación. Así como la adaptación progresiva de la normativa comunitaria al respecto. 
tuación laboral, ya que el otorgamiento o renovación de permisos suele estar ligado a la posesión de un empleo y un contrato de trabajo, lo que añade un factor de inestabilidad e inseguridad jurídica a quienes cuentan con trabajos precarios.

Las prácticas discriminatorias por motivos étnicos en el acceso al empleo y en la promoción interna en las empresas afectan sobre todo a los inmigrantes de países menos desarrollados que España ${ }^{15}$, en particular cuando los trabajadores se encuentran en posiciones de acceso a puestos de trabajo más precarios, y en función también del sector económico en el que se mueven. Lo que viene a confirmar una realidad ya apuntada de algún modo en párrafos anteriores, y es que en el mercado laboral español ya existe una forma de discriminación arraigada, más allá de los motivos raciales o culturales, y es la que se produce por motivos «socioeconómicos». Ello se suma en el caso de la inmigración al diverso origen o la diferente cultura, derivando en situaciones de discriminación aún más flagrantes y llamativas, si cabe.

Para algunos autores ${ }^{16}$, la exclusión de los trabajadores por motivos de raza o cultura se explica desde la relación de poder en la que los empresarios, como polo excluyente, tienen las manos libres para explotar a los inmigrantes. Tenemos que discrepar sin embargo de esta teoría porque la entendemos demasiado reduccionista, simplificando el conflicto a una pura relación de poder entre dos polos, el empresario y el trabajador, sin tener en cuenta que dentro de la convivencia diaria de la empresa como organización social pueden darse situaciones de discriminación entre los empleados y/o mandos inter-

15 En un estudio promovido por la OIT, dirigido a comprobar las prácticas empresariales ante la mano de obra marroquí masculina en el sector no agrícola, se mostró que en igualdad de condiciones los trabajadores autóctonos contaban con al menos el triple de oportunidades de ser contratados por los empleadores. Ante personas de igual currículum, edad y disponibilidad, las preferencias de los empresarios tienden a obstruir el acceso de estos inmigrantes por el solo hecho de su pertenencia nacional o étnica. Estas prácticas discriminatorias no se registran por igual en las diferentes ramas laborales: no se detecta prácticamente en la construcción, es algo mayor en la industria y muy elevada en el sector servicios. Ello muestra la importancia de la segmentación laboral y cómo la existencia de oportunidades de empleo para ciertos inmigrantes (i.e., magrebíes), se reduce a medida que abandonamos ciertas ocupaciones «habituales» de este colectivo. Ver COLECTIVO IOÉ. ¡No quieren ser menos! Exploración sobre la discriminación laboral de los inmigrantes en España. Comisión Ejecutiva Confederal UGT. Madrid, Octubre 2001.

${ }^{16}$ COLECTIVO IOÉ. ¡No quieren ser menos! Exploración sobre la discriminación laboral de los inmigrantes en España. Comisión Ejecutiva Confederal UGT. Madrid, Octubre 2001. 
medios que nada tienen que ver con la empresa como tal o con el empresario, o con la organización contratante; siendo en cambio una situación no deseable, tanto para la persona inmigrante afectada por supuesto, como para la organización empresarial en general, ya que a medio plazo repercute en su competitividad y calidad de servicio.

Con todo ello, podemos concluir que las nuevas formas de discriminación hacia los inmigrantes están ya lejos de un puro racismo biológico. De por sí el mercado laboral español es un mercado que se presta por su estructura y composición a una discriminación entre los mismos trabajadores, donde bien de forma expresa bien de manera solapada, se han venido dando situaciones discriminatorias de muy diferente índole. Y los inmigrantes las padecen, cargando las tintas en esas actitudes «racistas» para demarcar en esas personas una naturaleza diferente cuya convivencia con los españoles estaría llena de riesgos. En el mercado laboral, y más en la coyuntura económica actual, podemos decir que los inmigrantes padecen dos tipos de discriminación: una, por parte del empresario, que en muchos casos y según qué sectores económicos sigue siendo reacio a la contratación de los mismos, preso de prejuicios y estereotipos que no permiten ver que las diferencias culturales (que las hay), lejos de separar o crear dificultades, pueden por el contrario resultar muy necesarias para la empresa, en los tiempos actuales. Y en segundo lugar, la discriminación que sufren de parte de sus propios compañeros, de los otros trabajadores "autóctonos», que los ven como intrusos que quieren competir con los españoles en pie de igualdad.

\section{INSTRUMENTOS DE LUCHA FRENTE A LA DISCRIMINACIÓN}

\subsection{Instrumentos jurídicos}

La Constitución Española reconoce en su artículo 1 la igualdad junto a la libertad, la justicia y el pluralismo político, como uno de los valores superiores del ordenamiento jurídico. El reconocimiento constitucional de estos valores tiene importancia en la medida que supone la incorporación de un catálogo de derechos y libertades que no pueden ser afectados en su esencia por el legislador ordinario, puesto que la Constitución los reserva como elemento de limitación del poder.

Por otro lado, el artículo 13 del mismo texto señala que «los extranjeros gozarán en España de las libertades públicas que garantiza el presente título en los términos que establezcan los tratados y la 
ley». Ello supone que los derechos y libertades reconocidos a los extranjeros son derechos constitucionales y, como tales, dotados de la protección constitucional. Entre tales derechos y libertades está el de igualdad y no discriminación, que reconoce el artículo 14 al establecer la igualdad de todos los españoles ante la ley, sin que sea posible la admisión de ningún tipo de discriminación por motivo de nacimiento, raza, sexo, religión, opinión o cualquier otra condición o circunstancia personal o social.

Este concepto de igualdad ha evolucionado a lo largo del tiempo, merced entre otros a la jurisprudencia del Tribunal Constitucional ${ }^{17}$. Además, existe un derecho subjetivo a la igualdad de trato, que si bien no se puede predicar como derecho autónomo sino siempre en el marco de relaciones jurídicas concretas, limita la actuación de los poderes públicos así como la de las personas físicas y jurídicas, siempre en el marco de tales relaciones.

A partir de este escenario, el ordenamiento jurídico español ha ido incorporando disposiciones normativas y/o ha revisado los textos normativos para incorporar las prevenciones necesarias que doten a los agentes de los instrumentos precisos, tanto para ver garantizado este derecho como para poder responder ante los atentados que eventualmente pudiera sufrir. Por otro lado, la condición de España de miembro de la Unión Europea ha implicado la asunción de los acuerdos, decisiones y disposiciones normativas adoptadas en este ámbito supranacional. Todas ellas tienen su reflejo actualmente en el ordenamiento jurídico español; a continuación queremos hacer referencia a los instrumentos jurídicos existentes, tomando como referente la actividad al respecto desarrollada desde la Unión Europea ${ }^{18}$.

17 Véase en este sentido, RODRÍGUEZ-PIÑERO BRAVO-FERRER, M. y FERNÁNDEZ LÓPEZ, M. F. «Igualdad y discriminación», Madrid, 1986. Así como la doctrina recogida en las sentencias 34/1984, 161/1991 ó 39/2003 del Tribunal Constitucional; así como las del Tribunal Supremo de 17 de octubre de 1990, 23 de septiembre de 1993, 17 de mayo de 2000 o 18 de julio de 2002, entre otras. Desde el punto de vista de las relaciones laborales también ha habido pronunciamientos diversos sobre el principio de igualdad, como las Sentencias 52/1987, 136/1987 y 77/1993 del Tribunal Constitucional; y las de 13 de mayo de 1991, 22 de mayo de 1991, 27 de noviembre de 1991, 14 de octubre de 1993, 7 de julio de 1995 de la Sala de lo Social del Tribunal Supremo, entre otras.

18 No hay que olvidar además, otras disposiciones a nivel internacional, recogidas en la Declaración Universal de Derechos Humanos de 1848, o en los Pactos de Derechos Civiles y Políticos y de Derechos Económicos, Sociales y Culturales, de 1966. Asimismo, el Derecho Internacional del Trabajo se muestra comprometido en la consecución de la igualdad y la no discriminación en las relaciones laborales, como se desprende de diversas Declaraciones de la Organización Internacional del Trabajo 
El artículo 13 del Tratado de la Comunidad Europea, incluido por el Tratado de Ámsterdam, ofrece a la UE una base jurídica para combatir cualquier forma de discriminación al señalar que «sin perjuicio de las demás disposiciones del presente Tratado y dentro de los límites de las competencias atribuidas a la Comunidad por el mismo, el Consejo, por unanimidad, a propuesta de la Comisión y previa consulta al Parlamento Europeo, podrá adoptar acciones adecuadas para luchar contra la discriminación por motivos de sexo, de origen racial o étnico, religión o convicciones, discapacidad, edad u orientación sexual».

En el ejercicio de las competencias recogidas en este artículo 13, la Unión Europea aprobó el año 2000 dos directivas para aplicar estos principios:

- Directiva 2000/43/CE del Consejo, de 29 de junio de 2000, relativa a la aplicación del principio de igualdad de trato entre las personas independientemente de su origen racial o étnico.

- Directiva 2000/78/CE del Consejo, de 27 de noviembre de 2001, relativa al establecimiento de un marco general para la igualdad de trato en el empleo y la ocupación.

Básicamente, lo que hacen estas Directivas es introducir un conjunto de instrumentos jurídicos que facilitan la garantía de la igualdad de trato, protegiendo a todas las personas que pueden estar en situación de discriminación por su origen racial o étnico, su religión, su orientación sexual, etc.

En este sentido, la Directiva 2000/43, en su artículo 2 define que: «se entenderá por principio de igualdad de trato la ausencia de toda discriminación, tanto directa como indirecta, basada en el origen racial o étnico ${ }^{19}$.

Según esta disposición, existirá discriminación directa cuando por motivos de origen racial o étnico, una persona sea tratada de manera menos favorable de lo que sea pueda ser tratada otra en una si-

(así, la Declaración relativa a los Principios y Derechos Fundamentales en el Trabajo, de 1998). Por otro lado, y en el ámbito de la Unión Europea, hay que señalar que además de las Directivas referidas en este trabajo, la Carta de Derechos Fundamentales adoptada en el año 2000 reconoce el principio de igualdad y no discriminación.

${ }_{19}$ Asimismo entiende que la discriminación basada en el origen racial o étnico puede poner en peligro la consecución de objetivos que se han planteado a nivel europeo (Tratado CE) y en particular la consecución de un alto nivel de empleo y de protección social, la elevación del nivel y la calidad de vida, la cohesión económica y social y la solidaridad, y también puede hipotecar el objetivo de desarrollar la Unión Europea como un espacio de libertad, seguridad y justicia. (Considerando 9, Directiva Europea 43/2000). 
tuación comparable (por ejemplo, si en un anuncio de trabajo se indicara «absténganse de presentarse personas con discapacidad», o «no se aceptan negros»).

La discriminación será indirecta cuando una disposición o práctica aparentemente neutra sitúe a personas de un origen racial o étnico concreto en desventaja particular con respecto a otras personas, salvo que tal disposición o práctica pudiera justificarse de una manera objetiva con una finalidad legítima y salvo que los medios para la consecución de esta finalidad sean adecuados y necesarios (por ejemplo, la prohibición de llevar sombreros en el lugar de trabajo puede ser discriminación indirecta para algunas religiones, salvo que fuera requerido por motivos de seguridad).

En relación a la Directiva 2000/43, dispone que constituirá discriminación cuando se produzca un comportamiento no deseado relacionado con el origen racial o étnico que tenga como objetivo o consecuencia atentar contra la dignidad de la persona y crear un entorno intimidatorio, hostil, degradante, humillante, u ofensivo. Además la Directiva considera como discriminación la instrucción para discriminar entendida como aquella que recibe una persona para discriminar a otra.

En el caso de la primera Directiva, los Estados se comprometieron a su transposición a los respectivos ordenamientos jurídicos a más tardar para el 19 de julio de 2003 para la primera, y para el día 2 de diciembre de ese año en el caso de la segunda, admitiéndose en este último caso la posibilidad de una prórroga de tres años más para introducir los cambios necesarios relativos a la discriminación por motivos de discapacidad o de edad. Además, en el caso de la primera Directiva, los Estados debían contar también con un organismo encargado de prestar asistencia y asesoramiento de manera independiente a las víctimas de discriminación racial y, en su defecto, crear uno ${ }^{20}$.

${ }^{20}$ En la actualidad, en España existe el Observatorio Español del Racismo y la Xenofobia, creado al amparo de lo dispuesto en el artículo 71 de la Ley Orgánica 4/2000, de 11 de enero, de Derechos y Libertades de los Extranjeros en España y su Integración Social. Así como el Consejo para la Promoción de la Igualdad de Trato y No Discriminación de las Personas por el Origen Racial o Étnico, creado en base a la Ley 62/2003 de 30 de diciembre, de medidas fiscales, administrativas y de orden social. Corresponde a este organismo la promoción del principio de igualdad de trato y no discriminación de las personas por su origen racial o étnico en la educación, la sanidad, las prestaciones y los servicios sociales, la vivienda y en general, la oferta y el acceso a cualesquiera bienes y servicios, así como el acceso al empleo, a la actividad por cuenta propia y al ejercicio profesional, la afiliación y la participación en las organizaciones sindicales y empresariales, las condiciones de trabajo, la promoción profesional y la formación profesional ocupacional y continua. 
España ha incorporado estas Directivas en nuestro ordenamiento a través de la Ley 62/2003, de 30 de diciembre, de medidas fiscales, administrativas y de orden social, en cuyo artículo 34 se señala que el objeto es incorporar medidas que permitan que el principio de igualdad de trato y no discriminación sea real y efectivo en ámbitos como:

- El acceso al empleo.

- La afiliación y participación en organizaciones sindicales y empresariales.

- Las condiciones de trabajo.

- La promoción profesional.

- La formación profesional ocupacional y continua.

- En el acceso a la actividad por cuenta propia y al ejercicio profesional.

- En la incorporación y participación en cualquier organización cuyos miembros desempeñen una profesión concreta.

Asimismo realiza modificaciones en otras disposiciones con rango de ley que acogen el principio de igualdad, de cara a introducir en su articulado el nuevo concepto antidiscriminatorio. Las leyes modificadas son:

- El Estatuto de los Trabajadores ${ }^{21}$.

— La Ley de Integración Social de los Minusválidos.

En cuanto a sus competencias, desarrollará con plena autonomía funcional y con el apoyo del Observatorio Español del Racismo y la Xenofobia, entre otras: prestar asistencia independiente a las víctimas de discriminación directa o indirecta por origen racial o étnicos, a la hora de tramitar sus reclamaciones; realizar con autonomía e independencia análisis y estudios así como publicar informes independientes sobre la discriminación de las personas por motivos de origen racial o étnico y sobre el respeto al principio de igualdad; y promover medidas que contribuyan a la igualdad de trato y a la eliminación de la discriminación.

En todo caso, la realidad es que en los estudios del Eurobarómetro, la gran mayoría de los españoles y en general de los ciudadanos europeos, desconocen qué hacer y a quién dirigirse en el supuesto de sufrir algún tipo de discriminación. (http://ec.europa.eu/public_opinion/archives/ebs/ebs_296_en.pdf).

${ }_{21}$ En concreto, en sus artículos 4.2 y 17. El primero de ellos reconoce el derecho del trabajador a no ser discriminado directa o indirectamente para el empleo, o una vez empleado; y el segundo proclama el principio de no discriminación en las relaciones laborales prescribiendo la nulidad de los preceptos reglamentarios, las cláusulas de los convenios colectivos, los pactos individuales y las decisiones empresariales unilaterales que contengan discriminaciones directas o indirectas desfavorables sobre la base de los mismos factores de discriminación expresados en el artículo anterior. 
- La Ley sobre prestación transnacional de servicios.

- La Ley de Infracciones y Sanciones en el Orden de los Social.

Además de esta Ley, hemos de tener en cuenta además, la Ley Orgánica 3/2007, de 22 de marzo, para la igualdad efectiva entre mujeres y hombres, que avanza y mejora este ámbito legislativo. Así como el Código Penal, cuyo artículo 314 tipifica el delito de discriminación en el empleo.

En términos generales, es posible afirmar que el tratamiento normativo de la igualdad y no discriminación a nivel internacional, comunitario y estatal parece consolidado. Si bien ello no es óbice para articular nuevas herramientas complementarias o de apoyo a estos instrumentos jurídicos, sin caer en la redundancia en absoluto, cuanto más en la medida en que asistimos con demasiada frecuencia a supuestos de discriminación en el mundo laboral, pese a dichas normas.

\subsection{Iniciativas puestas en marcha por organizaciones sociales}

La existencia de un marco normativo y de políticas orientadas a garantizar la igualdad de trato no son garantía de nada, en realidad. Tanto más si no se dotan de los instrumentos y medidas necesarias para que tales disposiciones se puedan poner en práctica y ejecutar debidamente. De hecho se siguen dando grandes desigualdades que generan procesos discriminatorios entre las personas.

En este sentido, el Plan Estratégico de Ciudadanía e Integración 2007-2010 ya citado a lo largo de este trabajo, y publicado por el Ministerio de Trabajo y Asuntos Sociales se hace eco de esta situación a partir de los Informes de la Comisión Europea contra el Racismo y la Intolerancia (ECRI) y del Observatorio Europeo del Racismo y la Xenofobia de la UE (UEMC). Estos procesos discriminatorios son especialmente importantes en ciertos colectivos de inmigrantes por cuya posición social se encuentran en situación de mayor vulnerabilidad. Por otro lado, los datos del Centro de Investigaciones Sociológicas (CIS) indican que en los últimos cinco años han aumentado de forma sensible las actitudes reacias a la inmigración y que se mantienen e incluso incrementan los estereotipos y prejuicios en torno a la inmigración y los inmigrantes.

El mismo Plan reconoce que, pese a la existencia y a la identificación de estas conductas, la realidad es que no se dispone hasta la 
fecha de programas de apoyo a las víctimas de la discriminación, a nivel institucional. Ello explicaría el recurso creciente a la actividad desarrollada por organizaciones civiles como la Comisión Española de Ayuda al Refugiado ${ }^{22}$, o SOS Racismo ${ }^{23}$, por citar algunas, que ponen a disposición de estas personas una batería de actuaciones y de personal especializado a fin de dar rostro a estas situaciones de discriminación y que no queden impunes.

Por otro lado, se indica que no existe un sistema de recogida de datos sobre actos violentos debidos a motivos racistas o xenófobos. Los datos recogidos en este momento por el Ministerio del Interior en el Programa Estadístico de Seguridad se refieren a ilícitos penales y además al recoger los datos no se entra en los motivos, por lo que este dato se pierde.

Por lo que se refiere a actos discriminatorios más vinculados al mercado laboral, estamos en la misma situación, ya que únicamente se recogen los delitos relativos a la producción de una grave discriminación en el empleo público o privado, pero recogidos bajo el epígrafe genérico de "delitos contra los derechos de los trabajadores», con lo que no es posible conocer datos concretos sobre cuáles de estos delitos son producidos por discriminación en base a motivos étnicos o de raza. Tampoco se hace un seguimiento de las denuncias por discriminación ni de las sentencias dictadas con relación a ellas.

El Observatorio Español del Racismo y la Xenofobia, y la Comisión para la promoción de la igualdad de trato y no discriminación por raza o etnia arrojan la esperanza de poder disponer de herramientas con las que poner fin a esta situación, pero en cualquier caso resulta ya indicativo el hecho de que la propia Administración Pública se haga eco de esta situación y entone un trémulo «mea culpa» en este Plan Estratégico ${ }^{24}$.

\footnotetext{
22 www.cear.es

23 www.sosracismo.org/

${ }^{24}$ El Plan sigue haciendo un repaso de la triste situación existente en el Estado en lo que a lucha contra la discriminación se refiere, indicando que «no existen foros periódicos de encuentro sobre los procesos discriminatorios, sobre el racismo y la xenofobia, sobre las buenas prácticas en la gestión de la diversidad y la igualdad de trato, ni sobre las normas y jurisprudencia en este campo. Por ello, aunque reconoce que hay experiencias en la gestión de la diversidad y en prácticas antidiscriminatorias, no hay un intercambio de conocimiento y de buenas prácticas en estos ámbitos. Es notable además la falta de formación sobre igualdad de trato y gestión de la diversidad entre el personal público. Finalmente, se considera necesario abordar una revisión de la normativa vigente actual desde el punto de vista del respeto al principio de igualdad de trato y no discriminación.
} 
Ante esta situación, son muchas las organizaciones que han decidido poner en marcha sus propios programas de lucha contra la discriminación y de gestión de la diversidad. No hablamos en este caso de campañas reivindicativas o de sensibilización, puesto que entendemos que las mismas tienen su espacio ya en el ámbito habitual de actuación de este tipo de organizaciones. Por el contrario, nos estamos refiriendo a iniciativas y programas elaborados con el fin de extractar conclusiones y generar acciones concretas, que tengan repercusión en los agentes públicos y privados y contribuyan de esta forma a subsanar los problemas ya expuestos anteriormente.

En este contexto, el propio Plan Estratégico del Ministerio de Trabajo y Asuntos Sociales, antes citado, contempla varias líneas de acción que resumimos a continuación. Para posteriormente presentar algunas iniciativas llevadas a cabo por organizaciones civiles y que entendemos han aportado su granito de arena, siquiera sea en su ámbito territorial más inmediato, para combatir la discriminación, en particular en el ámbito laboral y empresarial.

Plan Estratégico de Ciudadanía e Integración 2007-2010. Ministerio de Trabajo y Asuntos Sociales.

Objetivo 1 Luchar contra la discriminación por motivo de origen racial o étnico en el marco de la lucha contra toda forma de discriminación, para garantizar la igualdad de oportunidades.

Programa IGU 1. Formación en materia de no discriminación e igualdad de trato.

Medida 1.1. Fomento de programas de formación de personal especializado en la lucha contra la discriminación.

Medida 1.2. Fomento de programas de formación dirigidos a empleados públicos en materia de normativa contra la discriminación por motivo de origen racial o étnico, en particular a fuerzas y cuerpos de la seguridad del Estado y la administración de justicia.

Medida 1.3. Fomento de programas de formación en materia de gestión de la diversidad dirigidos a empresarios y representantes de los trabajadores.

Programa IGU 2. Implicar a la ciudadanía en la lucha contra la discriminación y por la igualdad de trato.

Medida 2.1. Realización de actuaciones de sensibilización dirigidas a la población en general, a actores especialmente implicados en la lucha contra la discriminación y a la población inmigrante. 
Medida 2.2. Fomento de programas de información relativa a la igualdad de trato y no discriminación dirigida a la población en general.

Programa IGU 3. Identificación y promoción de buenas prácticas en materia de igualdad de trato y no discriminación.

Medida 3.1. Realización de foros de encuentro para el intercambio de buenas prácticas en materia de no discriminación en el acceso a los servicios públicos.

Medida 3.2. Realización de foros de encuentro para el intercambio de buenas prácticas en materia de no discriminación en la empresa privada.

Medida 3.3. Identificación de las estructuras de desigualdad y análisis de buenas prácticas en materia de igualdad de trato y no discriminación.

Medida 3.4. Elaboración de códigos de buenas conductas en materia de igualdad de trato en los servicios públicos y en las empresas privadas.

Programa IGU 4. Programa integral de atención a las víctimas de discriminación.

Medida 4.1. Fomento de actuaciones de atención a las victimas de discriminación.

Medida 4.2. Establecimiento y evaluación de protocolos de actuación para la atención a las víctimas de discriminación.

Medida 4.3. Fomento de programas de asesoramiento integral a las víctimas de discriminación.

Objetivo 2 Incluir la igualdad de trato en todas las políticas públicas.

Programa IGU 5. Fomento de las políticas antidiscriminación en las Administraciones Públicas.

Medida 5.1. Fomento de la inclusión de programas de atención a las víctimas de discriminación en los Planes de actuación de las Comunidades Autónomas y de las Corporaciones Locales.

Medida 5.2. Establecimiento de foros de intercambio y contraste de políticas antidiscriminación de las distintas Administraciones Públicas.

Medida 5.3. Análisis de la normativa en materia de discriminación, en particular en el ámbito sancionador. 
Programa IGU 6. Identificación de elementos de los procesos de discriminación.

Medida 6.1. Estudio análisis e identificación de los factores discriminatorios de la normativa a nivel estatal, autonómico y local.

Medida 6.2. Estudio, análisis e identificación de los factores y actores que intervienen en los procesos de discriminación.

Objetivo 3 Poner en marcha instrumentos de promoción de la igualdad de trato y no discriminación por origen racial o étnico.

Programa IGU 7. Puesta en marcha del Consejo para la promoción de la igualdad de trato y no discriminación de las personas por el origen racial o étnico.

Medida 7.1. Dotar al Consejo de los medios humanos y materiales necesarios para el cumplimiento de sus fines.

Medida 7.2. Promocionar y apoyar las actuaciones del Consejo para la promoción de la igualdad de trato y no discriminación de las personas por su origen racial o étnico.

Medida 7.3. Trasladar la puesta en marcha y actuaciones del Consejo al ámbito internacional, especialmente a las Instituciones y Estados miembros de la Unión Europea.

Programa IGU 8. Desarrollo del Observatorio Español del Racismo y la Xenofobia.

Medida 8.1. Realizar informes, estudios y encuestas y, proponer pautas de realización de los estudios y encuestas en materia de Racismo y Xenofobia elaborados por otras entidades.

Medida 8.2. Activar las relaciones con órganos y entidades internacionales que actúan en la lucha contra el racismo y la xenofobia.

Medida 8.3. Diseñar e implementar una red de recogida de datos en materia de trato discriminatorio.

Infórmate y Actúa. Guía contra la discriminación laboral para las empresas. Comisión Española de Ayuda al Refugiado (CEAR).

En el año 2007, CEAR pone en marcha, por segundo año consecutivo, una campaña de sensibilización para potenciar los aspectos positivos del acceso y permanencia en el mercado de trabajo de las personas inmigrantes, previniendo su discriminación, dentro del programa operativo de lucha contra la discriminación, financiado por el Ministerio de Trabajo y Asuntos Sociales y el Fondo Social Europeo. 
Esta campaña tiene un doble colectivo destinatario. Por un lado, las personas inmigrantes, a quienes se les intenta orientar sobre los pasos a dar en el supuesto de sufrir discriminación en el trabajo; y por otro, se dirige a las empresas, indicando una batería de medidas que pueden adoptarse ya sea para detectar situaciones de discriminación en los centros de trabajo, ya sea para prevenirlas. Además, se propone adherirse a la campaña incluyendo los logotipos de la misma en los sitios web y otras entradas de comunicación de las empresas.

Esta campaña ha venido completada por una serie de estudios e investigaciones realizadas desde CEAR-Euskadi, en colaboración con el anterior Departamento de Justicia, Empleo y Seguridad Social del Gobierno Vasco. En concreto, su «Dodecálogo de Recomendaciones para un tándem económicamente eficiente y socialmente responsable ${ }^{25}$ ", posiciona su planteamiento desde el ámbito de la responsabilidad social corporativa, como escenario óptimo para desarrollar iniciativas de gestión de la diversidad desde la perspectiva de enriquecimiento y aportación de ambas partes (inmigrante y empresa), superando postulados de culpables/inocentes y posiciones de poder. De esta forma, se presenta un conjunto de recomendaciones que, en última instancia, quieren ser un primer banco de propuestas de gestión de la inmigración en la empresa, planteando la gestión de la diversidad cultural en términos de normalización y viabilidad del proyecto empresarial, desde el convencimiento que toda empresa, cualquiera que sea su tamaño, se beneficia de la entrada de personal extranjero siempre que gestione correctamente sus recursos humanos y sus políticas de diversidad. Porque la pluralidad de culturas es una característica del mercado laboral del que selecciona la mano de obra, son necesarias pautas como las que propone CEAR-Euskadi para una gestión adecuada, efectiva y de calidad en la empresa.

El planteamiento de esta campaña es el que vamos a tener en cuenta para el lanzamiento de propuestas previsto en el apartado 4 de este documento.

\section{EqualRed}

EqualRed es un proyecto de la Iniciativa Comunitaria EQUAL desarrollado en la ciudad de Burgos en el año 2007, cuyo objetivo es

${ }^{25}$ CEAR EUSKADI. Dodecálogo de recomendaciones para un tándem económicamente eficiente y socialmente responsable. Bilbao 2006. Disponible en http://www.cear.es/files/Dodecalogo\%20de\%20Recomendaciones.pdf. 
facilitar el acceso y la reincorporación al mercado de trabajo de las personas con dificultades para ello. Entre las múltiples acciones que contiene, hay que destacar las referidas a la gestión de la diversidad cultural en las empresas ${ }^{26}$.

\section{Proyecto Empresa Integra. Murcia Acoge $e^{27}$}

La Asociación «Murcia Acoge» gestionó en el año 2004 este proyecto con el objetivo de promover la igualdad de oportunidades del colectivo inmigrante en el acceso y mantenimiento en el mercado de trabajo. Consistía en el desarrollo de una serie de actuaciones orientadas a propiciar un acercamiento de las empresas a la realidad de la inmigración, con el fin de fomentar una actitud positiva y prevenir posibles procesos discriminatorios.

\section{Proyecto $\operatorname{Nexos}^{28}$}

El Proyecto Nexos se presenta como una Agrupación de Desarrollo de carácter sectorial en el marco de la iniciativa comunitaria Equal, que integra varios agentes (Ministerio de Trabajo y Asuntos Sociales, Universidad Complutense de Madrid, Universidad de Barcelona, Cruz Roja Española, Consorcio de Entidades para la Acción Integral con Migrantes - CEPAIM) para la intervención positiva en las situaciones de discriminación, racismo y xenofobia que sufren los inmigrantes y las minorías étnicas, tanto en el acceso al empleo, como a nivel social y cultural. Contempla diversas acciones que van desde la formación y la investigación hasta acciones piloto como itinerarios de inserción o consejos de base territorial para la integración.

\section{OTRAS ALTERNATIVAS: COMBATIR LA DISCRIMINACIÓN "ACERCANDO LOS DOS POLOS»}

\subsection{Un punto de partida: Responsabilidad Social Corporativa e Innovación Social}

Como ya venimos comentando a lo largo de estas páginas, no es nuestro propósito plantear propuestas que demonicen el entramado

\footnotetext{
${ }^{26}$ Véase www.equalbur.org/imagenes/dossier-prensa/diario091107.jpg

27 www.murcia-acoge.com/

28 www.cepaim.org/ad_nexos/web/inicio.htm
} 
empresarial y el mercado laboral español, poniendo a la persona inmigrante en la posición inferior de debilidad y susceptible de ser discriminado y al que, por tanto, hay que proteger en todo caso y frente a todo. No se trata de anclarse en teorías de posiciones de poder o de superioridad, que en nuestra opinión no harían sino acrecentar aún los sentimientos negativos que como hemos visto están incrementando los procesos discriminatorios en diferentes ámbitos de la vida diaria.

El planteamiento que queremos hacer toma su punto de partida desde el concepto de diversidad cultural y, más concretamente y centrándonos en el mundo empresarial, desde el concepto de la gestión de los recursos humanos como factor elemental en el crecimiento de la empresa. Además, y para apoyar este planteamiento, entendemos que el escenario de la responsabilidad social corporativa aporta muchos elementos de interés y utilidad para dar forma a futuras iniciativas que pudieran suscitarse en este ámbito.

Empezaremos por tanto hablando de la gestión de la diversidad cultural, para después intentar encajarlo en los postulados de la responsabilidad social corporativa.

\section{La gestión de la diversidad cultural}

La primera cuestión que deberíamos poner sobre la mesa es por qué hablamos de la gestión de la diversidad cultural, y por qué suponemos que es necesaria para las empresas. Como bien señala Enrique García Ruiz de Galarreta, gerente del Colegio Oficial de Ingenieros de Álava, y Secretario de «Ingeniería para la Cooperación», en su introducción al «Dodecálogo de recomendaciones para un tándem económicamente eficiente y socialmente responsable ${ }^{29}$ » de CEAR-Euskadi, «la sociedad habla de inmigración y, definitivamente, las empresas, las asociaciones empresariales y los profesionales no podemos actuar y gestionar nuestras estrategias y recursos humanos como si la diversidad cultural no exigiera una atención especial. La exige, no nos engañemos; y cada vez más necesitamos que se nos asesore sobre cómo incorporar la interculturalidad en nuestras empresas.

Por convencimiento - porque creemos que la incorporación de inmigrantes a la empresa es enriquecedora-o por obligación - porque

${ }^{29}$ CEAR EUSKADI. Dodecálogo de recomendaciones para un tándem económicamente eficiente y socialmente responsable. Bilbao 2006. Disponible en http://www.cear.es/files/Dodecalogo\%20de\%20Recomendaciones.pdf. 
no hay mano de obra autóctona-lo cierto es que tarde o temprano nos vamos a encontrar con la necesidad de gestionar la diversidad cultural.

Como ante toda novedad, el empresariado puede afrontar esta realidad como una "amenaza"... o la puede abordar como una "oportunidad". (...) En una sociedad tan cambiante, las empresas han tenido que ir aprendiendo: sistemas de gestión de la calidad, del medio ambiente o la seguridad; incorporación de las tecnologías de la información, etc. Ahora se nos presenta el reto de aprender a gestionar la diversidad cultural, que - por referirse al capital humano, a las personas- es la mejor inversión tanto desde el punto de vista económico como social. ¿O es que queremos separar el ser "profesionales" y el ser "personas"? ${ }^{30}$ "

Por tanto, no se está «haciendo un favor» a las personas inmigrantes por incorporar este concepto en las empresas. No se trata de empresas «progres», ni alternativas, ni vinculadas de un modo especial con ciertas organizaciones. Hablamos de una realidad que se impone en todas las empresas, grandes y pequeñas, y que exige de ellas un esfuerzo, más o menos palpable, para tomar conciencia de esta realidad y adoptar las medidas oportunas.

Gestionar la diversidad cultural implica partir del hecho de que existen diferencias entre las culturas.* Las personas trabajamos de forma diferente en función de nuestra procedencia cultural ${ }^{31}$. Y eso

30 También encontramos referencias en el Gabinete de Prospección Sociológica de Gobierno Vasco, que tiene una publicación en línea con este estudio, también de CEAR-Euskadi, bajo el título Inmigración y Empresa. Apuntes para la gestión de la diversidad cultural en clave de comunicación y calidad, disponible en http://www1.euskadi.net/estudios_sociologicos/cuadernos_c.apl.

* Véase A. M. MARCOS DEL CANO, Inmigración, multiculturalismo y derechos humanos, Tirant Lo Blanch-UNED, 2009, Valencia, en el que se aboga por la gestión de la diferencia de un modo integrador.

31 Por ejemplo, en los países nórdicos y en los países de Europa del Este, los modelos educativos instruyen a las niñas y niños en jornadas escolares de 8 horas, lo cual les ayuda a llegar a la edad adulta preparados para afrontar jornadas laborales de 8 horas o más, similares a las que aquí tenemos. Sin embargo, en otros países del Sur la educación no se institucionaliza de esta manera, sino que es más reservada al entorno familiar desde el que se inculcan los valores y los conocimientos a los menores, sin la rigidez de los relojes y calendarios. Estas niñas y niños llegan a la edad adulta muy preparados para el desarrollo de actividades sociales pero poco acostumbrados a funcionar regidos por un autoritarismo horario. Esta falta de preparación les excluye, por tanto, de determinados procesos de selección de algunas empresas a las que llegan como inmigrantes, si bien les abre las puertas de otros procesos para empleos que no demandan maximización productiva del tiempo sino flexibilidad temporal. Véase al respecto COMISIÓN ESPAÑOLA DE AYUDA AL REFUGIADO. Segundo libro blanco de la integración sociolaboral de refugiadas, refugiados e inmigrantes. Madrid, 2007. Disponible en http://www.cear.es/files/II\%20libro\%20blanco.pdf 
no es bueno ni es malo, sencillamente es... diferente. Y reconocerlo tampoco nos hace racistas, ni presupone que estamos entendiendo que unas culturas son mejores que otras. El que el factor tiempo por ejemplo, se valore de manera diferente en los países nórdicos que en los países sudamericanos obedece a factores sociales y educativos diversos que no pueden sustentar comparaciones discriminatorias.

Es fácil caer en la tentación contraria, y de hecho asistimos diariamente a comentarios en este sentido, haciendo que estas diferencias culturales se conviertan en estereotipos afianzados en la cultural de la sociedad de acogida y que entonces sí, pueden ser discriminatorios, en especial desde el momento en que no se entienden como simples diferencias culturales sino como elementos que denotan la superioridad cultural de la sociedad de acogida ${ }^{32}$.

Ante estas diferencias culturales, la actitud de la empresa no puede ser, ni aceptarlas incondicionalmente, ni tampoco negarlas e intentar asimilar a sus personas trabajadoras extranjeras. Aquí radica precisamente el concepto de gestión, sobre la base del «ganar-ganar» de ambas partes que debe presidir la relación entre la persona trabajadora extranjera y la empresa. Esta estrategia permitirá a las empresas obtener provecho de los valores culturales heterogéneos de su plantilla, así como identificar las herramientas necesarias para explotar convenientemente esas diferencias, garantizando así una convivencia pacífica, productiva y rentable de un equipo de trabajo que, cada vez más, está llamado a ser culturalmente diverso.

El concepto de gestión es una realidad admitida en las empresas actualmente, como herramienta de organización interna y externa que garantiza estabilidad y rentabilidad. En esta gestión se han incorporado los recursos humanos y entre ellos hay que tener en cuenta los culturalmente heterogéneos, lo que nos lleva a las políticas de gestión de la diversidad cultural, que tímidamente están entrando en las empresas, no tanto como se desearía y aún de forma escasa en el escenario empresarial del Estado español.

Entendemos como gestión de la diversidad cultural el «conjunto de prácticas adaptadas a las necesidades y cultura de la empresa, puestas en

32 Entenderlo de esta forma resulta absurdo, ya que los elementos culturales son aprensibles y toda persona está capacitada para adaptarse a los estándares de comportamiento de un entorno laboral y cultural determinado. De hecho, sería ridículo plantear que un peruano por ejemplo, que estuviera trabajando en España, fuera incapaz de trabajar en una cadena de frenética producción de una empresa de montaje de automóviles, por suponer el caso. 
práctica en el ámbito de la empresa y referidas al personal como individuos; que crean igualdad de oportunidades e interacción y que conducen a una sinergia entre la diversa fuerza de trabajo, de modo que desarrollan entornos de trabajo incluyentes beneficiando a la empresa» ${ }^{33}$.

De esta definición podemos extractar las siguientes conclusiones preliminares:

- La gestión de la diversidad cultural forma o debe formar parte de la filosofía de la empresa.

- A través de ella se fomenta la interacción entre las personas que la integran, y con las aportaciones que cada uno puede realizar desde su personalidad y desde su bagaje cultural, se crean sinergias que redundan en beneficio de la organización.

- La gestión correcta de la diferencia permite o ha de permitir equipos de trabajo heterogéneos, enriquecidos, creativos y competentes para la empresa.

Una correcta gestión de la diversidad cultural exige, como no podía ser de otra forma, superar los estereotipos, es decir, esos clichés que alimentan procesos racistas o discriminatorios y que utilizamos cuando juzgamos a un grupo social o a alguno de sus miembros ${ }^{34}$.

El siguiente paso es identificar y conocer qué medidas se pueden poner en práctica para gestionar la diversidad en la empresa de una forma adecuada. Con relación a esta última cuestión han surgido ya algunas iniciativas desde organizaciones sociales de todo tipo, que toman como referente el escenario de la Responsabilidad Social Corporativa. Asimismo, hay que tener en cuenta las aportaciones de la Comisión Europea, en su Libro Verde sobre la Responsabilidad Social Empresarial ${ }^{35}$, así como de la UNESCO, en su Declaración Universal sobre la Diversidad Cultural ${ }^{36}$.

\footnotetext{
33 Definición de gestión de la diversidad realizada en el marco del Proyecto Transnacional PRO DIVERSITY (www.equalbur.org)

${ }^{34}$ ALTÉS RUFÍAS, E. ¿Cómo funcionan y para qué sirven los estereotipos en los medios de comunicación» www.bizkaia.net/Home2/Archivos/DPTO1/Noticias/ Adjuntos/297_mujeres.jornadas03.Ponencias.doc

35 COMISIÓN EUROPEA. Libro Verde «Fomentar un marco europeo para la responsabilidad social de las empresas». COM (2001) 366 final. Bruselas, 18.7.2001. Completado por la Comunicación de la Comisión relativa a la responsabilidad social de las empresas: una contribución empresarial al desarrollo sostenible. COM (2002) 347 final. Bruselas, 2.7.2002, y por la Comunicación de la Comisión al Parlamento Europeo, al Consejo y al Comité Económico y Social Europeo «Poner en práctica la asociación para el crecimiento y el empleo: hacer de Europa un polo de excelencia de la responsabilidad social de las empresas» COM (2006) 136 final. Bruselas, 22.3.2006.
} 
Entre estas iniciativas, en la línea de seguir el patrón de la responsabilidad social corporativa para incorporar en sus modelos de gestión herramientas de atención a la diversidad cultural, además de las iniciativas de grupos como EqualRed o CEAR ya comentados en el apartado anterior de este documento, no podemos perder de vista la importancia de la gestión de la diversidad en las empresas anglosajonas, hasta el punto que las empresas consultoras en recursos humanos ofrecen actualmente servicios punteros para desarrollar e implementar el plan de gestión de la diversidad en base a herramientas privadas propias.

En España se trata de un concepto que no está aún muy extendido. No obstante, se han puesto en marcha ciertos proyectos que pueden servir de pauta para entender que es necesario. Así, y además de los ya comentados, cabe destacar que en el año 2007 la Fundación Andaluza de Fondo de Fomento y de Empleo ${ }^{37}$ a petición del Observatorio de Español de Racismo y Xenofobia desarrolló la «Guía de Gestión de la Diversidad». En la Comunidad Autónoma de Euskadi, se han desarrollado varias herramientas y guías para diagnosticar la igualdad de género que pueden servir de referente. Los ejemplos incluyen:

- Guía Práctica para Diagnosticar la Igualdad de Oportunidades entre Mujeres y Hombres en las Empresas» desarrollada por Emakunde ${ }^{38}$,

- «Diagnóstico sobre Responsabilidad Social e Igualdad de Género» desarrollado por la Asociación Egiera»

Por otra parte, en términos de sellos de garantía, existen cada vez más iniciativas dirigidas a garantizar el origen ecológico o ético

36 UNESCO. Declaración Universal sobre la Diversidad Cultural. 2 de noviembre de 2001. En portal.unesco.org/es/ev.php-URL_ID=13179\&URL_DO=DO_TOPIC\&URL_ SECTION=201.html. Constituye el primer instrumento de los Estados para reafirmar su convicción de que el diálogo intercultural es el mejor garante de la paz, y rechaza la tesis que auguraba un choque entre culturas y civilizaciones, tras los atentados del 11 de septiembre. En él se eleva la diversidad cultural a la categoría de patrimonio común de la humanidad y se afirma en su artículo 1: "La cultura adquiere formas diversas a través del tiempo y del espacio. Esta diversidad se manifiesta en la originalidad y la pluralidad de las identidades que caracterizan los grupos y las sociedades que componen la humanidad. Fuente de intercambios, de innovación y de creatividad, la diversidad cultural, es, para el género humano, tan necesaria como la diversidad biológica para los organismos vivos. En este sentido, constituye el patrimonio común de la humanidad y debe ser reconocida y consolidada en beneficio de las generaciones presentes y futuras».

37 www.faffe.es

38 www.emakunde.euskadi.net/u72publicac/es/contenidos/informacion/pub_guias/ es_emakunde/adjuntos/guia_prac_diag_es.pdf 
de los productos fabricados. Asimismo se está trabajando tanto en Latinoamérica (mediante un proyecto del Banco Interamericano de Desarrollo) ${ }^{39}$ y en España (Emakunde ${ }^{40}$, Instituto de la Mujer ${ }^{41}$ ) en un sello de igualdad, que garantiza la igualdad de género en las empresas.

La responsabilidad social corporativa como modelo de incorporación de la gestión de la diversidad cultural

Siguiendo a la Comisión Europea, entendemos por responsabilidad social corporativa la integración voluntaria por parte de las empresas de las preocupaciones sociales y medioambientales en sus operaciones empresariales y en las relaciones con sus interlocutores $^{42}$. Ser socialmente responsable significa ir más allá del cumplimiento de las obligaciones jurídicas, invirtiendo en capital humano, en el entorno y en las relaciones con las partes interesadas. Ir más allá del cumplimiento estricto de la legislación, aportando como organización a la sociedad de la que se forma parte, retorna positivamente a la empresa en términos de mayor competitividad y productividad.

Hasta la fecha, el fomento de la responsabilidad social corporativa era algo exclusivo de grandes empresas y multinacionales. Sin embargo, su aplicación es importante y necesaria para cualquier empresa, con independencia de su tamaño y sector de actividad. De esta forma, algunas PYME ya asumen su responsabilidad social, mediante acciones de ámbito local; mientras que cooperativas, mutuas o asociaciones integran en sus estructuras los intereses de otras partes interesadas y asumen sus responsabilidades sociales y civiles.

El concepto de responsabilidad social corporativa comprende por tanto normas que incluyen aspectos sociales, laborales, medioambientales y de respeto de los derechos humanos:

— ISO 9000: Norma ISO de gestión de la calidad, que permite a las organizaciones adoptar un enfoque sistémico de la gestión de sus procesos, de modo que produzcan productos o servicios adaptados a las expectativas de sus clientes.

\footnotetext{
39 www.iadb.org/sds/WID/index_wid_s.htm

40 www.emakunde.euskadi.net

41 www.migualdad.es/mujer/index.html

42 COMISIÓN EUROPEA. Libro Verde «Fomentar un marco europeo para la responsabilidad social de las empresas». COM (2001) 366 final. Bruselas, 18.7.2001.
} 
— ISO 14000: Norma ISO de gestión medioambiental.

- ISO 26000: Norma ISO actualmente en desarrollo, que proporciona orientación sobre los principios que subyacen en la responsabilidad social y sobre las maneras de implementar la responsabilidad social en la actividad y gestión interna de cualquier tipo de organización. No obstante esta norma no pretende servir para propósitos de certificación, o uso regulatorio o contractual.

- RSE 165010: Estándar español basado en la norma ISO 26000 y publicado por AENOR en 2007 como guía para la gestión de la RSC en las empresas

- Norma SA 8000: norma internacional para la responsabilidad social, de carácter voluntario cuyo objetivo es asegurar el respeto de las normas básicas relacionadas con los derechos humanos.

- Norma SGE 21 (Forética): Sistema de gestión Ética y Socialmente Responsable, es la primera norma europea que establece los requisitos a cumplir por una organización para integrar la Responsabilidad Social Corporativa en su estrategia y gestión. La Norma SG21 permite también, de manera voluntaria, auditar los procesos y obtener una certificación en Gestión Ética y Responsabilidad Social ${ }^{43}$.

¿Tiene sentido hablar de la Responsabilidad Social Corporativa como punto de partida en la preparación de estrategias de lucha contra la discriminación y la consolidación de medidas de gestión de la diversidad cultural? Entendemos que sí, tanto en relación con problemas tradicionalmente planteados y no resueltos, como con respecto a nuevos desafíos que puedan surgir. Las medidas de respon-

${ }^{43}$ Esta norma está orientada a introducir valores éticos auditables medibles en las áreas de gestión de una organización que desee asumir un compromiso social. Es utilizada por entidades y empresas como Correos y Telégrafos, Novartis Farmacéutica, Bilbao Bizkaia Kutxa (BBK), Eurofirms ETT, Ciba Visión, ... y es compatible y/o complementaria a otras normas como ISO 9001 — para la calidad-, ISO 14000 -para el medioambiente—, GRI, Global Compact, OHSAS 18001 —para salud y seguridad-, SA8000 — para ámbito laboral_, EFR o Empresa Familiarmente Responsable - para la conciliación -... Y aunque no tiene el mismo rango que una ISO, a fecha de hoy es una de las pocas que puede utilizarse para certificar la gestión responsable de los recursos humanos en general (y de los recursos culturalmente diversos en particular), ya que no existe una norma ISO certificable. 
sabilidad social corporativa van más allá de las normas jurídicas como ya hemos dicho, y en lo que se refiere a las relaciones laborales, suponen algo diferente a la negociación colectiva. Tales medidas deben demostrar rapidez en la detección de problemas, innovación y originalidad en el planteamiento de soluciones, eficacia en su puesta en práctica y concreción en las acciones a llevar a cabo.

En la actualidad, los diferentes instrumentos en que se concretan las acciones de responsabilidad social corporativa de las empresas (i.e., declaraciones de principios, los marcos promocionales, los códigos de conducta y buenas prácticas, etiquetas sociales, los índices bursátiles éticos, las guías de elaboración de memorias de sostenibilidad, modelos de triple balance, modelos o estándares de gestión, etc.), contemplan menciones genéricas a los conceptos de igualdad y no discriminación ${ }^{44}$, si bien como un aspecto más, en el que tampoco se profundiza demasiado, en la mayoría de los casos: en casi todos los supuestos se contempla en tanto que reflejo del respeto al principio constitucional de igualdad, y siempre desde la consideración de medidas antidiscriminatorias en el seno de la empresa para conseguir la igualdad de trato. Es decir, da la sensación que la idea es articular medidas no tanto desde la perspectiva de un reconocimiento de la diversidad cultural de la empresa y la necesidad de su adecuada gestión, cuanto de un respeto a la normativa vigente adoptando medidas para combatir eventuales procesos discriminatorios, sin bajar a profundizar acerca de sus causas.

En este sentido, es interesante a título descriptivo reseñar los datos del estudio realizado por la Fundación Ecología y Desarrollo (ECODES), en su Anuario sobre la Responsabilidad Social Corporativa en España $2006^{45}$, donde analiza el tratamiento que las empresas del IBEX 35 dan a la igualdad de oportunidades en sus iniciativas de responsabilidad social corporativa:

\footnotetext{
${ }^{44}$ La referencia necesaria al principio de igualdad de trato en los documentos de responsabilidad social corporativa ya viene establecido en las normas evaluadoras vigentes. Así, la norma para la evaluación de la gestión ética y socialmente responsable en las organizaciones -FORÉTICA/SGE 21/versión 2005- obliga a las empresas a velar "para que las relaciones humanas en el seno de la misma se desarrollen en el marco de respeto legítimo de los principios de igualdad de trato y oportunidades, de forma específica en el acceso a los puestos de trabajo, a la formación, el desarrollo profesional y la retribución». De forma similar se expresan otros documentos como la norma SA 8000, las líneas directrices para empresas multinacionales de la OCDE, o la guía GRI para la elaboración de memorias de sostenibilidad (www. globalreporting.org/NR/rdonlyres/4 15 F 297 B-5289-4160-8 B 6C7CC034D5BE52/0/G3_GuidelinesESP.pdf.)

${ }_{45}$ Disponible en www.ecodes.org
} 
LA DISCRIMINACIÓN POR MOTIVOS ÉTNICOS O DE RAZA...

\begin{tabular}{|c|c|c|c|c|c|c|c|}
\hline Compañía & $\begin{array}{c}\text { Compromiso } \\
\text { general de no } \\
\text { discriminación }\end{array}$ & \begin{tabular}{|c} 
Por \\
razon \\
de sexo \\
y raza
\end{tabular} & $\begin{array}{c}\text { Por } \\
\text { razon } \\
\text { de edad }\end{array}$ & \begin{tabular}{|c|} 
Por \\
razon \\
de \\
religión
\end{tabular} & \begin{tabular}{|c|} 
Por \\
razon de \\
orientación \\
sexual
\end{tabular} & \begin{tabular}{|c|} 
Aplicables \\
a todas las \\
operaciones \\
en todo el \\
mundo
\end{tabular} & \begin{tabular}{|c|} 
Compromiso \\
de no \\
discriminación \\
respecto a \\
discapacitados
\end{tabular} \\
\hline Abertis & Sí & No & No & No & No & No & Sí \\
\hline Acerinox & No & No & No & No & No & No & No \\
\hline ACS & No & No & No & No & No & No & No \\
\hline Altadis & Sí & Sí & No & Sí & Sí & Sí & No \\
\hline Amadeus & No & No & No & No & No & No & No \\
\hline Arcelor & Sí & Sí & No & No & No & No & $\overline{\text { Sí }}$ \\
\hline Banesto & Sí & No & No & No & No & Sí & No \\
\hline $\begin{array}{l}\text { Bilbao Vizcaya } \\
\text { Argentaria }\end{array}$ & Sí & Sí & Sí & Sí & Sí & Sí & Sí \\
\hline Banco Popular & No & No & No & No & No & No & No \\
\hline Banco Sabadell & Sí & Sí & No & No & No & Sí & Sí \\
\hline $\begin{array}{c}\text { Santander Central } \\
\text { Hispano }\end{array}$ & Sí & Sí & No & Sí & No & Sí & No \\
\hline Bankinter & Sí & No & No & No & No & No & No \\
\hline Enagas & No & No & No & No & No & No & No \\
\hline Endesa & Sí & Sí & No & Sí & No & Sí & No \\
\hline FCC & No & No & No & No & No & No & No \\
\hline Gamesa & Sí & No & No & No & No & No & No \\
\hline Gas Natural & Sí & No & No & No & No & No & No \\
\hline Acciona & No & No & No & No & No & No & No \\
\hline Ferrovial & Sí & Sí & Sí & Sí & No & Sí & Sí \\
\hline Iberdrola & No & No & No & No & No & No & No \\
\hline Iberia & Sí & Sí & Sí & Sí & Sí & Sí & Sí \\
\hline Indra & Sí & No & No & No & No & No & No \\
\hline Mapfre & Sí & No & No & Sí & No & Sí & No \\
\hline Metrovacesa & No & No & No & No & No & No & No \\
\hline NH Hoteles & No & No & No & No & No & No & No \\
\hline Prisa & No & No & No & No & No & No & No \\
\hline $\begin{array}{l}\text { Red Eléctrica } \\
\text { Española }\end{array}$ & Sí & No & No & No & No & No & No \\
\hline Repsol-YPF & Sí & Sí & Sí & Sí & Sí & Sí & Sí \\
\hline Sogecable & No & No & No & No & No & No & No \\
\hline Telefónica & Sí & Sí & No & Sí & No & Sí & No \\
\hline Telefónica Móviles & Sí & Sí & No & Sí & No & Sí & No \\
\hline TPI & No & No & No & No & No & No & No \\
\hline Unión Fenosa & Sí & No & No & No & No & Sí & No \\
\hline Zeltia & No & No & No & No & No & No & No \\
\hline
\end{tabular}

Fuente: Fundación Ecodes - Anuario sobre Responsabilidad Social Corporativa en España 2005.

(C) UNED. Revista de Derecho UNED, núm. 6, 2010 
Como podemos observar, todavía estas normas tienen un impacto limitado en la gestión de la diversidad y el establecimiento de entornos contrarios a situaciones de discriminación por razones étnicas o de raza.

Aunque en el mundo anglosajón sí existen planes de diversidad en las organizaciones, como consecuencia de un mayor arraigo del fenómeno migratorio y del concepto de interculturalidad, en el caso español la incidencia es aún escasa, limitándose como podemos observar a compromisos genéricos, que rara vez bajan al detalle de las acciones emprendidas; y esto en el caso de las empresas indicadas, que se supone son grandes corporaciones a las que de por sí se les supone cierto compromiso con su entorno tan sólo sea por su incidencia en el mismo ${ }^{46}$. Si habláramos de otro perfil de empresas, la valoración sería bastante peor.

El planteamiento que queremos hacer en este trabajo es cómo podría ser posible que, sobre la base de las normas existentes en materia de responsabilidad social corporativa, y en concreto tomando como referencia la Norma SGE 21, puede ser posible articular un sistema de auditoria o valoración de la correcta gestión de la diversidad cultural de las empresas que:

- No sea costoso para las empresas.

- Tenga un valor multiplicador en términos de reconocimiento de la organización en el mercado.

46 No obstante, algunas empresas, además de proclamar su compromiso con la igualdad de oportunidades en relación con la selección de personal y las condiciones de trabajo, hacen mención expresa de las concretas iniciativas puestas en marcha. En ese sentido, es justo destacar la Memoria de Responsabilidad Social Corporativa del Grupo Santander, en la que se recogen algunas de las políticas de integración desarrolladas por la compañía en las diferentes empresas del grupo y en sus distintas sedes. Así, se hace mención del «Plan de Acción Positiva» en el marco de la discriminación por razón de sexo, de la creación de grupos de seguimiento del trabajo de personas discapacitadas, o de distintas acciones llevadas a cabo por la compañía en sus sedes de distintos países Iberoamericanos. Otras empresas, como el Grupo Eroski, destacan por reconocer la igualdad de oportunidades de cara al disfrute de diversos beneficios sociales ofrecidos a los empleados con independencia del nivel de su puesto de trabajo; y por equiparar a las parejas de hecho y de derecho en relación con tales beneficios. En esa misma línea MRW destaca por su particular compromiso con la integración de las personas discapacitadas y colectivos con dificultades de acceso al empleo, ofreciendo en su memoria amplia información acerca de las iniciativas adoptadas en ese sentido (firma de acuerdos con sociedades de la Fundación ONCE, compras y apoyo técnico a Centros Especiales de Empleo, etc.). 
- Garantice medidas de gestión de la diversidad cultural en la empresa que sean beneficiosas para la organización y para la plantilla.

\subsection{Otras propuestas}

Sobre la base de este planteamiento, queremos sugerir una nueva línea de trabajo que incorpore prácticas de gestión de la diversidad cultural en las empresas, desde la perspectiva de la responsabilidad social corporativa, con dos objetivos añadidos a los comentados en el apartado anterior:

- Aunque quiere tener como destinatario a cualquier tipo de empresa, cualquiera que sea su tamaño y sector, quiere ir dirigido en particular a las pequeñas y medianas empresas, que tienen un menor contacto con estas nuevas líneas de gestión empresarial.

- Ha de ser «rentable» para la organización que lo implemente, valorado este concepto en términos de visibilidad en el mercado.

En definitiva, se trata de articular una herramienta que tenga de cara a clientes y proveedores un impacto similar al que pueden tener iniciativas ya gestionadas actualmente como las medidas de protección medioambiental, por ejemplo. Ello exige una acción complementaria, cual es la de sensibilización de la sociedad con relación al fenómeno discriminatorio, puesto que sólo así será verdaderamente valorada la actuación llevada a cabo por la empresa.

La implementación de un modelo de gestión de la diversidad cultural en la empresa ha de traer consigo una serie de beneficios, ya identificados por diversas organizaciones estudiosas de este tema ${ }^{47}$ :

- Atracción, reclutamiento y mantenimiento de personal de un amplio fondo de talentos.

47 Entre otros podemos ver: Asociación EqualRed- PRO DIVERSITY Transnational Project. (www.equalbur.org/imagenes/dossier-prensa/diario091107.jpg). También la Asociación de desarrollo NEXOS Guía para la gestión de la diversidad en las empresas (www.cepaim.org/ad_nexos/web/inicio.htm); CEAR-EUSKADI. Dodecálogo de recomendaciones para un tándem económicamente eficiente y socialmente responsable. Bilbao, 2006. Disponible en http://www.cear.es/files/Dodecalogo\%20de\% 20Recomendaciones.pdf. También la Comisión Europea contra la discriminación ha editado materiales diversos sobre los beneficios que reporta a la empresa la gestión eficaz de la diversidad. 
- Mayor motivación e implicación del personal, lo que se traduce, entre otros, en una reducción de los gastos laborales y del absentismo, por ejemplo.

- Aportación a la flexibilidad y la responsabilidad del personal.

- Fomento de la implicación, la ética del trabajo y el «esfuerzo discrecional» de los asalariados.

- Mejor asimilación del impacto de la globalización y del cambio tecnológico.

- Incremento de la productividad y afianzamiento del talento.

- Fortalecimiento de la creatividad y de la innovación.

- Mejora de los conocimientos acerca de cómo operar en culturas diferentes.

- Mayor comprensión de las necesidades de los clientes habituales.

- Asistencia en el desarrollo de nuevos productos, servicios y estrategias de mercado.

- Creación de oportunidades para grupos desfavorecidos, fomentando la cohesión social.

- Mejora de la imagen y reputación de la empresa respecto a agentes externos.

En cuanto al planteamiento de la mencionada iniciativa para la implantación de un "estándar de calidad» o similar en las empresas que destaquen por el desarrollo de actuaciones favorables a la gestión de la diversidad cultural, nos basaríamos en una de las herramientas actualmente existentes en el Estado ya mencionada, la norma SGE 21:2005 Sistema de gestión ética y socialmente responsable, orientada a introducir valores éticos auditables medibles en las áreas de gestión de una organización interesada en asumir un compromiso social. Esta norma ya es utilizada por varias entidades, como Correos y Telégrafos, Novartis Farmacéutica, Bilbao Bizkaia Kutxa, etc. Es compatible y/o complementaria a otras normas como ISO 9001 (para calidad), ISO 14000 (para medioambiente), GRI Global Compact, OHSAS 18001 (para salud y seguidad), SA8000 (para ámbito laboral), o EFR-Empresa Familiarmente Responsable (para la conciliación), entre otros. Bien es cierto que SGE 21 no tiene el mismo rango que una ISO, pero en este momento es de las pocas herramientas que nos pueden servir de instrumentos de base para certificar la gestión responsable de los re- 
cursos humanos en general ${ }^{48}$. Además de SGE 21, queremos considerar igualmente el modelo GRI (Global Reporting Initiative ${ }^{49}$ ), estándar internacional que no requiere auditoria o certificación, y que es utilizado por algunas empresas que apuestan por la gestión de la diversidad cultural, a la hora de elaborar su memoria anual. Mientras la norma SGE 21 se centra en el sistema de gestión, el modelo GRI se centra en reportar sobre los resultados de la empresa a nivel económico y sociolaboral por un lado, y medioambiental por otro.

\section{Metodología de trabajo}

La identificación de las características de un proyecto como el que se propone exige dedicar una fase preliminar de análisis del contexto y entorno de trabajo, a fin de extraer parámetros de referencia en base a metodologías y diagnósticos ya existentes o en estudio, en el ámbito de la igualdad y la gestión de la diversidad entendida en sentido amplio y bajo las premisas de la responsabilidad social corporativa. En este sentido, podemos considerar por ejemplo, las siguientes acciones principales:

- Estudio de las normas internacionales y españolas de responsabilidad social corporativa y análisis detallado de la cobertura a la discriminación por nacionalidad, raza o etnia.

- Estudio de las herramientas existentes (metodologías, diagnósticos, estándares).

- Contacto con organizaciones que apliquen y gestionen tales instrumentos.

- Identificación de aspectos a mejorar de estos instrumentos, para configurar uno propio, más depurado, a nivel de proyecto.

- Análisis de cobertura de las herramientas y sus resultados.

- Identificación de puntos comunes entre tales instrumentos y el propuesto a nivel de proyecto.

- Elaboración de estrategia final de desarrollo e implementación.

- En base a los resultados obtenidos en esta fase, habrá que definir la metodología o cuadernos de trabajo con las empresas.

${ }^{48}$ Está previsto que salga una norma ISO 26000 próximamente, pero será certificable o auditable, sino que será simplemente una guía de buenas prácticas.

49 www.globalreporting.org/home 
La metodología a desarrollar en el seno de una empresa para implementar un sistema de gestión de la diversidad requiere un análisis del contexto o situación de la empresa en particular, la identificación de los indicadores de medida del estado y diagnóstico de situación, la definición de las acciones a llevar a cabo para la implementación del sistema de gestión, y finalmente la evaluación y seguimiento continuo.

\section{ANÁLISIS DEL CONTEXTO}

Se trata de estudiar la situación en que se encuentra la empresa por un lado y, por otro, definir las áreas de la misma sobre la que se realizará el diagnóstico. Respecto de la primera cuestión, será necesaria una entrevista a nivel de mandos superiores e intermedios y con representantes de los trabajadores para identificar la situación de diversidad existente, cómo se gestionan los conflictos, y detectar así el escenario de trabajo de la empresa en concreto que haga posible «personalizar» los indicadores de diagnóstico.

Por otro lado, entendemos que la aplicación de esta metodología debe abarcar diferentes áreas de la gestión de la organización en el ámbito de los recursos humanos, lo que exige una reflexión previa en cuanto a las funciones que integran o deben integrar la gestión de los recursos humanos de una empresa. A priori es posible distinguir cuatro grandes áreas:

- Reclutamiento y selección.

- Formación.

- Evaluación del rendimiento y promoción.

- Políticas salariales.

- Tratamiento de situaciones de reducción de personal.

\section{INDICADORES Y DIAGNÓSTICO}

Uno de los aspectos principales a considerar es la configuración de un sistema de indicadores y elementos de valoración que simplifiquen el itinerario de estudio y análisis de la situación en cada organización. La identificación de estos elementos se realizará conforme a los resultados obtenidos de las fases previas comentadas. Además, no se debe perder de vista la situación detectada desde la perspectiva 
de la población inmigrante, ya que la percepción de la discriminación por este colectivo es fundamental para enfocar adecuadamente la metodología en su conjunto. Por ello, en esta fase se trata de establecer grupos de trabajo en los dos ámbitos (inmigración y empresa), proponiendo una serie de entrevistas y actividades grupales que faciliten la selección de los elementos de juicio a tener en cuenta. Se trata en este caso de establecer grupos de trabajo con los que realizar una serie de entrevistas y actividades grupales orientadas a diagnosticar el grado de gestión de la diversidad cultural en la empresa, si es que existe. En este sentido existen actualmente diversos patrones que se pueden tomar como modelo, tales como los que ofrece el Programa Latinoamericano de RSE (IARSE) ${ }^{50}$. El mismo centra la cuestión en torno a dos grandes indicadores en torno a los cuales se plantean una serie de preguntas y actividades:

a) Valoración de la diversidad

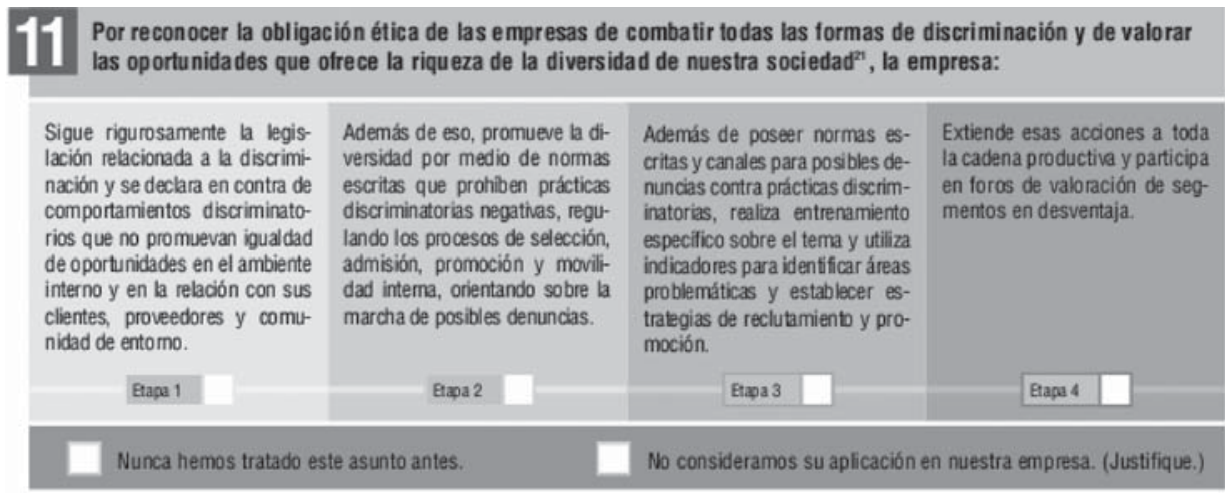

Sí No

La política de valoración de la diversidad y no discriminación consta en el código de conducta y/o en la declaración de valores de la empresa?

Esta política contempla explícitamente:

¿La cuestión étnico racial?

¿La cuestión de la edad?

¿La cuestión religiosa?

50 INSTITUTO ARGENTINO DE RESPONSABILIDAD SOCIAL EMPRESARIA. Guía de Autoaplicación. Indicadores de Responsabilidad Social Empresaria, versión 1.0. Córdoba, Argentina. Junio 2009. 
¿La cuestión de la orientación sexual?

¿La cuestión de origen geográfico y clase social?

¿La cuestión de las personas con necesidades especiales?

¿La cuestión de la apariencia física?

$¿$ La empresa incluye requisitos de la diversidad en los procesos y herramientas de gestión de personas para gestionar la diversidad de sus equipos y posibles desigualdades en relación a los colectivos antes citados?

¿De esta política son derivados procedimientos formales para procesos de selección, admisión, promoción y movilidad interna y despido?

¿En esta política están previstos los mecanismos y canales formales para la presentación de denuncias, análisis y esclarecimiento de posibles casos de discriminación?

¿De la política de valoración de la diversidad y no discriminación se derivan políticas específicas de inclusión para pueblos originarios y minorías étnicas discriminadas?

\section{b) Compromiso con la igualdad y no discriminación}

Considerando los hechos de discriminación y las desventajas que caracterizan la situación de la población de diferentes orígenes raciales 0 étnicos, la empresa:

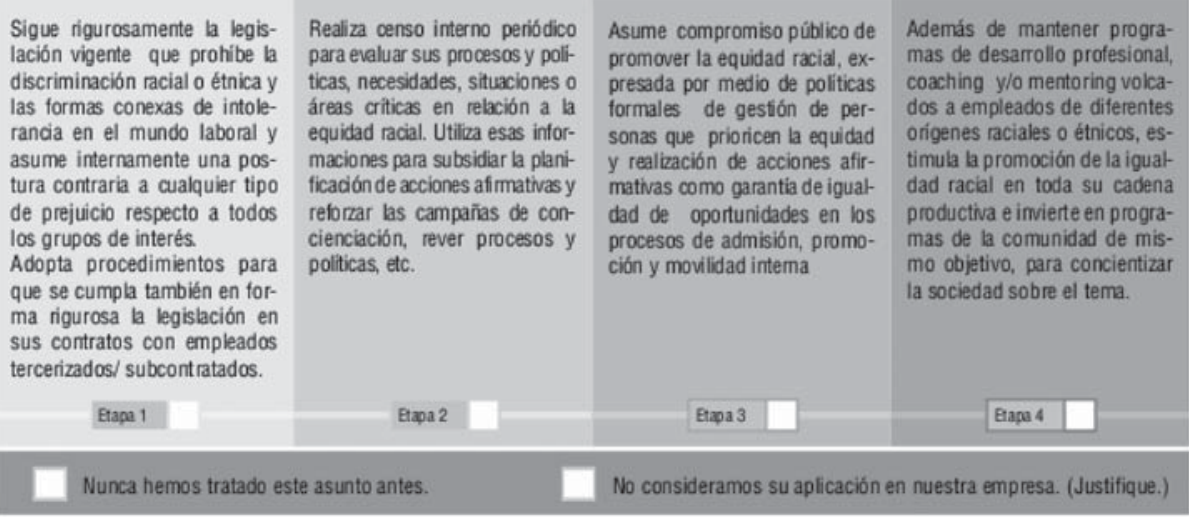

¿La política de promoción de la igualdad y no discriminación es formal y consta en el código de conducta y/o en la declaración de valores de la empresa? 
¿De esta política se derivan procedimientos específicos para mejorar la calificación y el desarrollo profesional de los empleados de diferentes orígenes étnicos y nacionales?

¿Se realizan campañas internas de sensibilización para mejorar la comprensión de la importancia y necesidad de la gestión de la diversidad, suprimiendo cualquier atisbo de discriminación por origen étnico o racial?

¿La política de comunicación comercial tiene como premisa no utilizar figuras estereotipadas o que atenten contra la población de diferente nacionalidad u origen étnico?

Porcentual de personal de diverso origen étnico o racial con respecto al total de empleados, 2007, 2008, 2009,2010

Estas preguntas son orientativas. A la hora de preparar los indicadores que han de servir para realizar el diagnóstico hay que tener en cuenta las características que queremos que este tenga:

- Debe ser instrumental, es decir, un medio para identificar ámbitos de actuación y definir nuevas herramientas de trabajo. El diagnóstico sólo tiene sentido si es para formular a continuación un plan de trabajo que incluya acciones concretas.

- Debe ser aplicado, es decir, práctico. Se trata de recoger datos y analizar situaciones que orienten a la empresa en la toma de decisiones en este ámbito.

- Debe ser flexible, o adaptado a las necesidades de cada empresa.

- Por último, tiene que se dinámico o en permanente actualización, a fin de que pueda resultar útil también en la evaluación de los resultados.

\section{Definición de las acciones a llevar a Cabo}

Una vez que contamos con el diagnóstico, es el momento de preparar el programa de gestión de la diversidad cultural en la empresa en cuestión. Como señala la Agrupación de Desarrollo Nexos ${ }^{51}$, son tres los criterios que deben presidir este momento:

- Gestión por objetivos y planificación.

${ }^{51}$ AGRUPACIÓN DE DESARROLLO NEXOS. Guía de gestión de la diversidad cultural en las empresas (www.cepaim.org/ad_nexos/web/inicio.htm) 
- Compromiso, comunicación, información. Todas las personas que forman parte de la empresa deben saber lo que se está haciendo y cuáles son sus objetivos.

- Participación y cooperación. Es importante implicar a todos los niveles de la plantilla en el diseño de este programa. Hay que procurar que los sistemas de trabajo sean lo más cooperativos posibles, evitando subgrupos de trabajo.

Las acciones a implementar pueden ser de distinta índole, y se pueden agrupar en diferentes áreas ${ }^{52}$ :

- Políticas de recursos humanos:

- Incentivar la diversidad cultural en los procesos de selección, reclutamiento, remuneración y promoción de personal dentro de la empresa, con independencia de las ayudas públicas a las que se pueda optar en su caso: ampliar los medios de reclutamiento, traducir los anuncios a diferentes idiomas; utilizar en la definición del puesto un lenguaje no sexista y respetuoso con la diversidad; elaborar un dossier de acogida conforme a la diversidad, ...

- Iniciativas de comunicación:

- Desarrollar herramientas formales e informales de comunicación interna que sean respetuosas con el plurilingüismo de las personas trabajadoras.

- Incorporar en la memoria de responsabilidad social corporativa un apartado dedicado a las políticas de inclusión de hombres y mujeres inmigrantes en la plantilla.

- Editar folletos o desarrollar estrategias de marketing que den a conocer a clientes y proveedores la política de la empresa y los beneficios derivados de incorporar la gestión de la diversidad cultural en la empresa.

- Interacción con el tercer sector, colaborando en iniciativas relacionadas con la diversidad cultural.

- Gobierno Corporativo y ambiente laboral:

- Promocionar la integración de la diversidad cultural a nivel de alta dirección.

52 RIBERA, A. Guía para la gestión de la diversidad y la inclusión. Manual de la Empresa Responsable. Madrid. Biblioteca empresarial. Cinco Días, 2004, pp. 209-228. 
- Crear comités de gestión de la diversidad cultural para revisar periódicamente que la integración de esta diversidad se realice conforme a los criterios de respeto y responsabilidad social.

- Gestionar adecuadamente las necesidades de los empleados derivadas de la diversidad religiosa (celebración de festividades, vestimenta, etc.), de manera que resulte un acuerdo conforme tanto para las necesidades de la empresa como para el personal afectado.

- Revisar los servicios y prestaciones de la empresa con relación al personal empleado, teniendo en cuenta la diversidad (i.e., comedores de empresa, regalos corporativos, cesta de navidad, etc.).

- Desarrollar acciones de conciliación laboral y familiar.

- Formación:

- Técnicas de trabajo en equipo y dinámicas de grupo.

- Comunicación verbal y no verbal.

- Técnicas de gestión de conflictos.

- Sensibilización sobre la importancia de la diversidad cultural y la necesidad de inclusión.

- Entrenamiento en la identificación de estereotipos y prejuicios.

- Talleres en educación en inteligencia emocional, para aprender a controlar el desarrollo de de filias o fobias grupales o individuales.

\section{Evaluación}

La evaluación de la política de gestión de la diversidad cultural que se adopte es imprescindible para poder realizar un seguimiento adecuado de su implantación e impacto en la empresa. A priori no resulta fácil medir los resultados obtenidos de estas políticas, ya que no es sencillo aislar los resultados de este ámbito del resto de factores que inciden en la actividad normal de la empresa.

En cuanto a los instrumentos de evaluación, podemos utilizar los genéricos utilizados habitualmente en los cuadros de mando o en 
la gestión de calidad en general ${ }^{53}$, y encargarlo bien a una empresa externa e independiente, o bien a medios internos de la empresa que cuenten en todo caso con la suficiente autonomía y libertad para realizar esta valoración.

Los resultados de esta evaluación pueden traducirse a su vez en diferentes acciones que permitan un feed-back en las propias políticas de gestión de la diversidad, tales como por ejemplo:

- Divulgación de la evaluación: boletines, Internet, Intranet, encuentros de buenas prácticas, etc.

- Publicación de un informe sobre la diversidad en la empresa y/o dedicación de un capítulo específico en la memoria corporativa anual.

- Entrevistas y cuestionarios periódicos con los trabajadores para conocer su percepción sobre este tema.

Asimismo, como resultado de la evaluación realizada sobre las acciones ejecutadas en la empresa, puede definirse un sello de calidad o compromiso de la empresa en cuestión con la gestión de la diversidad cultural, de manera que pueda publicitarse adecuadamente por los medios de comunicación habituales de la corporación, así como darlo a conocer entre proveedores y clientes, de forma similar a como se realiza actualmente en los supuestos de cumplimiento de estándares de calidad, respeto al medioambiente, etc. Obviamente, esta propuesta tendría un valor meramente testimonial en este momento, ya que no existe una norma de calidad al respecto que sea auditable y medible; pero entendemos que puede ser un interesante punto de partida para, al menos, llamar a la reflexión y provocar el progreso en esta línea de trabajo.

\section{CONCLUSIONES}

Como podemos observar, se impone la gestión de la diversidad cultural en las empresas como una realidad necesaria en un entorno cambiante, de cara a asegurar la competitividad de las corporaciones en un nuevo entorno. Perpetuarse en clichés y estereotipos relativos a

${ }^{53}$ El grupo Sodexo ha puesto en marcha una batería de indicadores denominado «Sodexo Diversity Index (SDI)», donde se miden diferentes elementos relacionados con la gestión de la diversidad de la empresa. Disponible en uds.uvm.edu/documents/ 2007_diversity_report.pdf, y www.sodexousa.com/usen/Images/2008Diversityand InclusionReport_tcm87-101198.pdf 
ciertas culturas, religiones, etnias o razas es un anacronismo que únicamente repercute de forma negativa en el desarrollo de las sociedades y las economías de acogida.

No obstante sería iluso afirmar esto llanamente sin reconocer que queda todavía mucho por hacer. Las encuestas y estudios realizados a nivel estatal y europeo revelan que la ciudadanía en general sigue percibiendo la discriminación como una realidad, y con más frecuencia de la deseada asistimos a conflictos y casos de racismo y discriminación a diferente escala que nos hacen recordar el largo camino que queda aún por recorrer.

Entendemos que las líneas de acción deben ir por una doble vía:

- Por un lado, la de la sensibilización de la sociedad de acogida, lo que pasa por normalizar los procesos de control y lucha de la discriminación, implantando de forma efectiva y dando a conocer a todos los ciudadanos y ciudadanas los mecanismos legales e institucionales existentes para denunciar y combatir las situaciones que puedan darse en tal sentido. De manera que la discriminación llegue a ser identificada por la población como algo rechazable y que no admite justificación alguna, en línea con lo que ha sucedido por ejemplo con la violencia de género.

Para llevar a cabo este proceso es necesario que las Administraciones Públicas completen los procesos iniciados a nivel normativo, y lleven realmente a la práctica las propuestas definidas en sus planes estratégicos, complementándolo con actuaciones en centros cívicos, educativos, sanitarios, y también a nivel empresarial... en general, a nivel de la sociedad en general, para "normalizar» el rechazo a la discriminación y consolidar la realidad diversa de la sociedad.

- Por otro lado, y centrándonos ya a nivel de la empresa, es necesario reconocer que el escenario de la responsabilidad social corporativa en el que entendemos debe residir todo esfuerzo sobre la gestión de la diversidad cultural en las corporaciones, es algo novedoso relativamente, en particular en el Estado Español, y más si nos centramos en las pequeñas y medianas empresas.

En todo caso, consideramos que es el único escenario posible de trabajo y punto de partida, en el marco del cual es imprescindible la implicación de las instituciones públicas y organismos profesionales, que garanticen el cumplimiento y la 
continuidad de tales medidas. A este respecto, sería recomendable el diseño de una norma para la gestión de la diversidad, en línea con las normas ISO o SGE 21, que sistematizara todos los procedimientos a seguir por una empresa para ayudarla a gestionar y promover la diversidad cultural en su organización bajo los principios de igualdad y no discriminación.

Además, y de forma complementaria, debería promoverse otro tipo de acciones, como por ejemplo observatorios de diversidad, de composición plural (empresas, organismos públicos, tercer sector, ...), destinados a monitorizar y auditar los compromisos adquiridos por las empresas a nivel de gestión de la diversidad. A partir de aquí se podrían poner en marcha acciones complementarias, como encuentros, intercambios de experiencias, etc., que contribuyan a la divulgación de los resultados obtenidos y a la continuidad de los mismos.

Desde nuestro punto de vista, no estamos ante un imposible o ante una utopía, ya que existen muchas iniciativas puestas en marcha en entornos próximos al nuestro que demuestran que es posible y además necesario, gestionar adecuadamente la diversidad para que lo que nos hace distintos no nos haga distantes.

\section{BIBLIOGRAFÍA DE REFERENCIA}

ALTÉS RUFÍAS, E. ¿Cómo funcionan y para qué sirven los estereotipos en los medios de comunicación". (www.bizkaia.net/Home2/ Archivos/DPTO1/Noticias/Adjuntos/297_mujeres.jornadas03. Ponencias.doc)

CEPAIM. Guía de la gestión de la diversidad cultural en las empresas. Proyecto acción 3. Iniciativa Comunitaria Equal. En www.cepaim.org/ad_nexos/web/inicio.htm

COLECTIVO IOÉ. Ciudadanos o intrusos: la opinión pública espanola ante los inmigrantes. Madrid 2005. En www.nodo50.org/ioe/

COLECTIVO IOÉ. Dimensiones de la inmigración en España. Impactos y desafíos. En www.nodo50.org/ioe/

COLECTIVO IOÉ. Discriminación de los inmigrantes en el trabajo. En Sociedad y Utopía, n. ${ }^{\circ}$ 16, 2000. En www.nodo50.org/ioe/

COLECTIVO IOÉ. ¡No quieren ser menos! Exploración sobre la discriminación laboral de los inmigrantes en España. Unión General de Trabajadores, Madrid, 2001. En www.nodo50.org/ioe/ 
COMISIÓN ESPAÑOLA DE AYUDA AL REFUGIADO. Dodecálogo de recomendaciones para un tándem económicamente eficiente y socialmente responsable. Bilbao, 2006.

COMISIÓN ESPAÑOLA DE AYUDA AL REFUGIADO. Guía contra la discriminación laboral para las empresas. Madrid, 2007.

COMISIÓN ESPAÑOLA DE AYUDA AL REFUGIADO. Inmigración y empresa. Apuntes para la gestión de la diversidad cultural en clave de comunicación y calidad. En Cuadernos Sociológicos Vascos, n. ${ }^{\circ}$ 19. Lehendakaritza, Dirección de Estudios y Régimen Jurídico. Gabinete de Prospección Sociológica. Vitoria-Gasteiz, 2006.

COMISIÓN EUROPEA. Contra la discriminación, por la diversidad. En www.stop-discrimination.info

COMISIÓN EUROPEA. Discrimination in the European Union: perceptions, experiences and attitudes. Special Eurobarometer 296. Fieldwork february-march 2008. Brussels, July 2008.

COMISIÓN EUROPEA. Igualdad y no discriminación. Informe anual 2005. Bruselas, abril 2005.

COMISIÓN EUROPEA. Poner en práctica la asociación para el crecimiento y el empleo: hacer de Europa un polo de excelencia de la responsabilidad social de las empresas Comunicación de la Comisión al Parlamento Europeo, al Consejo y al Comité Económico y Social Europeo.. COM (200) 136 final. Bruselas, 22.03.2006.

COMISIÓN EUROPEA. Tercer informe anual sobre inmigración e integración. Comunicación de la Comisión al Parlamento Europeo, al Consejo, al Comité Económico y Social Europeo y al Comité de las Regiones. COM (2077) 512 final. Bruselas, 11.09.2007.

COMISIÓN EUROPEA. Libro Verde "Fomentar un marco europeo para la responsabilidad social de las empresas». COM (2001) 366 final. Bruselas, 18.07.2001.

COMISIÓN EUROPEA. La responsabilidad social de las empresas: una contribución empresarial al desarrollo sostenible. Comunicación de la Comisión al Parlamento Europeo, al Consejo y al Comité Económico y Social Europeo. COM (2002) 347 final. Bruselas, 02.07.2002

EMAKUNDE. Guía práctica para diagnosticar la igualdad de oportunidades entre hombres y mujeres en las empresas. Vitoria-Gasteiz, mayo 2006. 
GLICK, N., BASCH, L. y BLANC-SZANTON, C. (de). Towards a transnational perspective on migration. Race, class, ethnicity and nationalism reconsidered. The New York Academy of Sciences, New York, 1992.

INSTITUTO ARGENTINO DE RESPONSABILIDAD SOCIAL EMPRESARIA. Guía de Autoaplicación. Indicadores de Responsabilidad Social Empresaria. Programa Latinoamericano de RSE. IARSE, versión 1.0. Córdoba, Argentina, junio 2009.

INSTITUTO ARGENTINO DE RESPONSABILIDAD SOCIAL EMPRESARIA. Responsabilidad social empresaria e inclusión económica y social. Cómo las empresas pueden crear alternativas de inclusión económica y social para los emprendimientos productivos de base social. Guía de primeros pasos. Versión 2.0. Córdoba, Argentina. Octubre 2008.

MARCOS DEL CANO, A. M., «Inmigración y minorías», en O. PÉREZ DE LA FUENTE, Una discusión sobre la gestión de la diversidad cultural, Instituto de Derechos Humanos Bartolomé de las Casas, Universidad Carlos III de Madrid, 2008, pp. 55-82.

MARCOS DEL CANO, A. M., Inmigración, multiculturalismo y derechos humanos, Tirant Lo Blanch-UNED, Valencia, 2009.

MINISTERIO DE TRABAJO E INMIGRACIÓN. Boletín Estadístico de Extranjería e Inmigración. Número 19, Madrid febrero 2009.

MINISTERIO DE TRABAJO Y ASUNTOS SOCIALES. Plan Estratégico de Ciudadanía e Integración 2007-2010. Madrid 2007.

ORGANIZACIÓN INTERNACIONAL DEL TRABAJO. La hora de la igualdad en el trabajo. Informe global con arreglo al seguimiento de la Declaración de la OIT relativa a los principios y derechos fundamentales en el trabajo. Conferencia Internacional del Trabajo, 91 ${ }^{\mathrm{a}}$ reunión 2003. Ginebra, 2003.

ORGANIZACIÓN INTERNACIONAL DEL TRABAJO. Informe Mundial de la OIT: Insidia e inseguridad - la nueva cara de la discriminación y la desigualdad en el ámbito del trabajo. Revista de la OIT, n. ${ }^{\circ}$ 59, Abril 2007.

PROYECTO FILOXENIA, PROYECTO NEXOS, PROYECTO ARENA, PROYECTO RESEM-SENET (Agrupaciones de Desarrollo Iniciativa Equal). MINISTERIO DE TRABAJO Y ASUNTOS SOCIALES. Buenas prácticas y recomendaciones para la lucha contra el racismo y la xenofobia en el mercado de trabajo. Madrid, 2003. 
RIBERA, A. Guía para la gestión de la diversidad y la inclusión. Manual de la Empresa Responsable. Madrid. Biblioteca empresarial. Cinco Días, 2004, pp. 209-228.

UNESCO. Declaración Universal sobre la Diversidad Cultural. 2 de noviembre de 2001. En portal.unesco.org/es/ev.php-RL_ID=13179

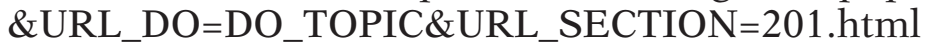


